\title{
Toxoplasmose animal no Brasil
}

\author{
Animal Toxoplasmosis in Brazil
}

Cristina Germani Fialho', Mariana Caetano Teixeira² \& Flávio Antônio Pacheco de Araujo³

\begin{abstract}
RESUMO
A toxoplasmose é causada pelo Toxoplasma gondii, parasito pertencente ao reino Protista, filo Apicomplexa, ordem Eucoccidiida e família Sarcocystidae. É um coccídeo intracelular obrigatório, que infecta naturalmente o homem, os animais selvagens e domésticos, e também os pássaros. É uma infecção de ampla distribuição geográfica e depende de alguns fatores como clima, condição socioeconômica e cultural. Os hospedeiros definitivos são os membros da família Felidae. A infecção ocorre pela ingestão de oocistos, taquizoítos, ou bradizoítos, e em algumas espécies, também por transmissão transplacentária e transmamária. É uma doença de importância em Saúde Pública, pelas alterações que causa nos fetos humanos, e de importância em produção animal pelas perdas por aborto. O diagnóstico laboratorial pode ser realizado pela demonstração do coccídeo (parasitológico), por métodos indiretos (imunológico) e por métodos de biologia molecular. A doença possui tratamento, mas não existem, atualmente, vacinas para toxoplasmose humana, apenas há uma vacina comercial para ovinos e estudos em outras espécies animais.
\end{abstract}

Descritores: Toxoplasma gondii, Protista, Apicomplexa.

\section{ABSTRACT}

Toxoplasmosis is caused by Toxoplasma gondii, a parasite which belongs to the kingdom Protista, phylum Apicomplexa, order Eucoccidiida and family Sarcocystidae. It is an obligate intracellular coccidian, which naturally infects human beings, wild and domestic animals, as well as birds. It is a geographically wide spread infection and it depends on some factors such as climate, social-economic and cultural conditions. The definitive hosts are members of the family Felidae. The infection occurs by the ingestion of oocysts, tachyzoites or bradyzoites, and in some species it also happens by transplacental and transmammary transmission. It is a disease of great importance for Public Health, because the alterations it causes in human fetuses, and concerning animal production due to abortion losses. Laboratorial diagnostics may be done by the demonstration of coccidian (parasitological), by indirect methods (immunologic) and by methods of molecular biology. This disease has treatment, but currently there are no vaccines for human toxoplasmosis, only a commercial vaccine for ovine and studies with other animal species.

Keywords: Toxoplasma gondii, Protista, Apicomplexa.

${ }^{1}$ Doutoranda. ${ }^{2}$ Mestranda, Programa de Pós-graduação em Ciências Veterinárias (PPGCV), Faculdade de Veterinária (FaVet), Universidade Federal do Rio Grande do Sul (UFRGS), Porto Alegre, RS/Brasil. ${ }^{3}$ Setor de Protozoologia, Departamento de Patologia Clínica Veterinária, FAVET-UFRGS. CORRESPONDÊNCIA: F.A.P. Araujo [faraujo@ufrgs.br]. 


\section{INTRODUÇÃO}

A toxoplasmose é causada pelo Toxoplasma gondii, parasito pertencente ao reino protista, filo Apicomplexa, ordem Eucoccidiida e família Sarcocystidae [121,122]. Esse parasito é um coccídio intracelular obrigatório, que infecta naturalmente o homem, os animais selvagens e domésticos, e também os pássaros. Os hospedeiros definitivos são os felídeos, pois só neles ocorre o ciclo sexuado do parasito, com a eliminação de oocistos que no ambiente esporulam e se tornam infectantes [113].

A patogenia e sinais clínicos são bem variados, ocorrendo desde casos benignos com febre e discreto aumento ganglionar, até casos de grave comprometimento do sistema nervoso central, alterações oculares provocando cegueira, ou aborto [157,205]. A infecção natural dos hospedeiros em geral, é principalmente adquirida pela ingestão de cistos através do consumo de carne crua ou mal cozida ou através de oocistos em alimentos contaminados [147].

\section{HISTÓRICO}

Têm-se realizado levantamentos da infecção toxoplásmica em quase todos os continentes desde o relato do protozoário, em 1908, por Nicolle \& Manceaux, na Tunísia, África [158, 159] e Splendore, na cidade de São Paulo, Brasil [212].

O primeiro caso de toxoplasmose humana foi descrito por Castellani, em 1913 [174], em um menino com quadro febril e com esplenomegalia. Em animais, pode-se citar como primeiros relatos: em cães, na Itália [40]; em ovinos, nos EUA [218]; em suínos, nos Estados Unidos [76] e, em caprinos, também nos Estados Unidos [77].

Foi demonstrado que o $T$. gondii podia ser transmitido pela exposição a fezes de felinos [108], e posteriormente foi comprovado que a infectividade estava relacionada com um pequeno coccídeo eliminado juntamente com as fezes desses animais $[67,88]$. No período de 1975-1976, foi descrito o ciclo selvático do parasito, evidenciando que não só os felinos domésticos eram os responsáveis pela perpetuação do protozoário [174].

\section{EPIDEMIOLOGIA}

A toxoplasmose é, do ponto de vista epidemiológico, uma infecção de ampla distribuição geográfica, pois está presente em todo planeta, com índices de soropositividade variando de 23 a $83 \%$, dependendo de alguns fatores: climáticos, socioeconômicos e cultu-rais. A infecção ocorre em todos os mamíferos e aves [157].

Felinos infectam-se por ingestão de taquizoítos (pseudocistos) ou bradizoítos (cistos) de tecidos de roedores ou de carne crua de outras espécies ofere-cidas a eles. Também pela ingestão de oocistos esporu-lados [174, 219], por transmissão transplacentária [117] e transmamária [176]. A chave da epidemiologia da toxoplasmose parece ser o gato de rua, por serem os únicos hospedeiros da forma sexuada, e a areia e o solo contaminados por fezes contendo oocistos, serem fontes duradouras de infecção [15]. Além disso, soma-se o fato de que os felinos cobrem suas fezes, aumentando as condições de sobrevivência do oocisto. A presença de oocistos no solo foi relatada por vários autores [55,103,112]. Para ocorrer esporulação, são neces-sárias condições ideais de umidade, oxigenação e tempe-ratura, podendo o oocisto permanecer infectante por até 18 meses [113].

Surtos de toxoplasmose em humanos foram relatados por muitos autores [21,59,149], a partir de consumo de carne mal-cozida, verduras e água conta-minadas. Em um estudo foi verificado que a proporção de humanos que adquiriram infecção pelo $T$. gondii foi mais alta na população que tem o hábito de comer carne mal-passada [8]. O risco de infecção por esse protozoário aumenta pelo consumo de carne de suínos, seguido da de ovinos e caprinos [97]. Após a ingestão de oocistos ou cistos, e liberação de taquizoítos para a circulação sanguínea e linfática, se o hospedeiro intermediário for uma fêmea gestante, o parasito pode invadir os tecidos do feto [20].

Não há uma grande evidência de importância epidemiológica dos cães na transmissão desta parasitose. No caso de cães rolarem em fezes de gatos contendo oocistos, eles não esporulariam no pelo dos cães, provavelmente pela inadequada temperatura e umidade. Mas os oocistos esporulados de $T$. gondii podem atravessar o trato intestinal dos caninos e serem excretados nas fezes nesse mesmo estágio infeccioso [125].

\section{TOXOPLASMOSE EM ANIMAIS}

\section{Toxoplasmose em felinos}

Existe uma elevada soroprevalência de $T$. gondii nos gatos, mas a doença clínica é rara, pois o ciclo 
enteroepitelial não costuma produzir sinais clínicos. Navarro et al. [153] inocularam experimentalmente gatos e observaram hipertermia, corrimento ocular, quadro pulmonar e fezes pastosas a líquidas. Houve inclusive a morte de um animal que estava eliminando oocistos. A infecção transplacentária pode causar aborto ou nascimento de filhotes com sinais clínicos severos, podendo causar morte [64].
Outras pesquisas foram realizadas no intuito de observar oocistos. Foram examinadas fezes de 15 felinos com até quatro meses de idade, encaminhadas ao Laboratório de Protozoologia da UFRGS - RS, e 13 (86,6\%) apresentaram oocistos tipo Toxoplasma [42]. Um estudo retrospectivo sobre pesquisas de oocistos, no mesmo laboratório, entre os anos de 1986 a 1990, e obtiveram $20 \%$ de positividade [22].

Tabela 1. Prevalência de anticorpos para Toxoplasma gondii em gatos, no Brasil.

\begin{tabular}{|c|c|c|c|}
\hline ESTADO & TESTE & PREVALÊNCIA & REFERÊNCIAS \\
\hline SP & SF & 50,8 & Sogorb et al. (1972) [206] \\
\hline $\mathrm{AM}$ e RO & HAI & 90,63 & Ferraroni \& Marzochi $(1978) *$ \\
\hline $\mathrm{AM}$ & HAI & 81 & Ferraroni et al. $(1980) * *$ \\
\hline $\mathrm{RS}$ & HAI & 24 & Mendez et al. (1983) [141] \\
\hline SP & HAI & 59 & Santos et al. (1983) [185] \\
\hline $\mathrm{RS}$ & HAI & 40,7 & Chaplin et al. (1984) [44] \\
\hline SP & IFI & 25,9 & Rosa et al. (1987) [181] \\
\hline $\mathrm{RS}$ & HAI & 10,2 & Bracini et al. (1992) [22] \\
\hline SP & IFI & 37,7 & Camargo et al. (1998) [30] \\
\hline SP & ELISA & 27,8 & Lucas et al. (1998) [127] \\
\hline PR & IFI & 73 & Garcia et al. (1999) [96] \\
\hline SP & IFI & 17,7 & Lucas et al. (1999) [126] \\
\hline $\mathrm{SP} / \mathrm{PR}$ & IFI & 19,4 & Langoni et al. (2001) [116] \\
\hline SP & ELISA & 40 & Meireles (2001) [138] \\
\hline PR & IFI & $\begin{array}{c}\text { Zona urbana: } 45 \\
\text { Zona peri-urbana: } 81,81\end{array}$ & Carletti et al. (2002) [35] \\
\hline SP & MAT & 26,3 & Silva et al. (2002) [196] \\
\hline SP & $\begin{array}{l}\text { IFI } \\
\text { MAD }\end{array}$ & $\begin{array}{l}18 \\
19\end{array}$ & Silva, Cutolo \& Langoni (2002) [191] \\
\hline $\mathrm{RS}$ & HAI & 37 & Araújo et al. (2003) [13] \\
\hline RJ & $\begin{array}{c}\text { HAI } \\
\text { ELISA }\end{array}$ & $\begin{array}{l}19,5 \\
2,55\end{array}$ & Netto et al. (2003) [156] \\
\hline PR & MAT & 84,4 & Dubey et al. (2004) [69] \\
\hline RO & $\begin{array}{l}\text { MAT } \\
\text { IFI }\end{array}$ & $\begin{array}{l}87,3 \\
87,3\end{array}$ & Cavalcante et al. (2004) [38] \\
\hline SP & MAT & 35,4 & Pena et al. (2006) [169] \\
\hline PR & IFI & 17,2 & Vargas (2006) [222] \\
\hline SP & IFI & 25 & Bresciani et al. (2007) [25] \\
\hline PR & IFI & 16,3 & Cruz (2007) [56] \\
\hline $\mathrm{RS}$ & $\begin{array}{l}\text { HAI } \\
\text { IFI }\end{array}$ & $\begin{array}{l}26,94 \\
37,96\end{array}$ & Pinto (2007) [173] \\
\hline
\end{tabular}

* apud Vidotto (1992) [229] ** apud Frenkel (1997) [87] 
Tabela 2. Prevalência de anticorpos para Toxoplasma gondii em cães, no Brasil.

\begin{tabular}{|c|c|c|c|}
\hline ESTADO & TESTE & PREVALÊNCIA & REFERÊNCIAS \\
\hline PR & SF & 51,5 & Giovanoni (1958) [100] \\
\hline $\mathrm{RJ}$ & SF & 79,2 & Coutinho $(1968)^{*}$ \\
\hline GO & SF & 57,1 & Fernandes \& Barbosa (1972) [78] \\
\hline SP & IFI & 72 & Ishizuka, Miguel \& Brogliato (1974) [111] \\
\hline SP & SF & 90 & Sogorb et al. (1976)* \\
\hline SP & IFI & 71,90 & Larson $(1976)^{*}$ \\
\hline $\mathrm{AM}$ e RO & HAI & 68,43 & Ferraroni \& Marzochi (1978)* \\
\hline $\mathrm{AM}$ & HAI & 63 & Ferraroni et al. $(1980)^{* *}$ \\
\hline RS & HAI & 3,1 & Chaplin et al. (1984) [43] \\
\hline SP & IFI & 63,8 & Ishizuka \& Yasuda (1981) [110] \\
\hline RS & HAI & 21 & Chaplin et al. (1984) [44] \\
\hline SP & IFI & 63,8 & Salata et al. $(1985)^{*}$ \\
\hline SP & IFI & 91 & Germano, Erbolato \& Ishizuka (1985) [99] \\
\hline PR & IFI & 37,84 & Freire et al. (1991)* \\
\hline RS & HAI & 4,96 & Braccini et al. (1992) [22] \\
\hline MG & IFI & $47,30 \%$ & Guimarães et al. (1992) [106] \\
\hline MG & HAI & 52,7 & Duran et al. (1997) [72] \\
\hline MG & $\begin{array}{c}\text { HAI } \\
\text { IFI } \\
\text { ELISA }\end{array}$ & $\begin{array}{c}22,5 \\
35 \\
35\end{array}$ & Silva et al. (1997) [194] \\
\hline RS & HAI & 37,37 & Lagaggio et al. (1997) [114] \\
\hline PR & IFI & 23,40 & Navarro et al. (1997) [150] \\
\hline SP & IFI/ELISA & 80 & Domingues et al. (1998) [62] \\
\hline MG & ELISA & 52,70 & Cabral et al. (1998) [29] \\
\hline PR & IFI & 84,1 & Garcia et al. (1999) [96] \\
\hline SP & ELISA & 81,28 & Higa et al. (2000) [107] \\
\hline SP & ELISA & 50,5 & Meireles (2001) [138] \\
\hline SP & $\begin{array}{l}\mathrm{HAI} / \mathrm{IFI} / \\
\text { ELISA/IB }\end{array}$ & 33 & Mineo et al. (2001) [144] \\
\hline PR & MAT & 21,3 & Souza et al. (2003) [208] \\
\hline PR & IFI & 61,9 & Souza et al. (2001) [209] \\
\hline MT & IFI & 35 & Souza et al. (2001) [211] \\
\hline SP & IFI & 51,19 & Varandas et al. (2001) [221] \\
\hline PR & IFI & $\begin{array}{c}\text { Zona urbana: } 46,82 \\
\text { Zona peri-urbana: } 68,96\end{array}$ & Carleti et al. (2002) [211] \\
\hline RO & IFI & 76,40 & Cañón-Franco et al. (2003) [32] \\
\hline $\mathrm{PE}$ & IFI & 46,60 & Coelho, Kobayashi \& Carvalho Jr. (2003) [48] \\
\hline SP & $\begin{array}{l}\text { IFI } \\
\text { MAD }\end{array}$ & $\begin{array}{l}18 \\
19\end{array}$ & Silva, Cutolo \& Langoni (2002) [191] \\
\hline $\mathrm{BA}$ & IFI & 63,55 & Barbosa et al. (2003) [17] \\
\hline SP E PR & MAT & 21,30 & Souza et al. (2003) [208] \\
\hline RO & IFI & 77,90 & Cavalcante et al. (2004) [39] \\
\hline MG & ELISA & 30,30 & Mineo et al. (2004) [145] \\
\hline PB & IFI & 45,10 & Ragoso et al. (2004) [177] \\
\hline PR & IFI & 45,73 & Reis et al. (2004) [178] \\
\hline MG & IFI & 62,20 & Rosado, Guimarães \& Oliveira (2004) [183] \\
\hline PB & IFI & 45,10 & Azevedo et al. (2005) [16] \\
\hline SP & IFI & 33,1 & Langoni et al. (2006) [115] \\
\hline PR & IFI & 20,8 & Romanelli et al. (2007) [180] \\
\hline SP & MAD & 26 & Gonçalez (2008) [101] \\
\hline
\end{tabular}




\section{Toxoplasmose em caninos}

A toxoplasmose clínica foi relatada pela primeira vez em um cão em Turim, na Itália, por Mello [40]. Carini, no Brasil [34], observou infecção aguda fatal em um cão jovem.

Os sinais clínicos em cães podem envolver os sistemas neuromuscular, respiratório e gastrointestinal [63]. Em avaliação da presença de anticorpos para $T$. gondii em 80 cães com sintomatologia nervosa, foi detectada IgG em 26 animais $(32,5 \%)$ e IgM em 25 $(31,2 \%)$ [27]. Em cães inoculados experimentalmente, foi observado aumento de temperatura em todos, num período de 7 a 14 dias, além de outros sintomas moderados. Porém um cão apresentou sintomatologia severa, incluindo anorexia, diarréia e alterações respiratórias [195]. Num outro experimento, foi observado em todos os cães, linfonodos aumentados e a presença de taquizoítos na urina e no sangue, além de alteração ocular em 7 do total de 9 cães [2]. Foi descrita toxoplasmose ocular em cães jovens por inocu-lação experimental [1]. A infecçção transplacentária, produzindo aborto e morte fetal, foi verificada após a inoculação experimental de T. gondii em cadelas durante a gestação [24].

Tabela 3. Prevalência de anticorpos para Toxoplasma gondii em caprinos, no Brasil.

\begin{tabular}{|c|c|c|c|}
\hline ESTADO & TESTE & PREVALÊNCIA & REFERÊNCIAS \\
\hline BA & HAI & 10 & Amaral, Santos \& Rebouças (1978) [7] \\
\hline $\mathrm{RS}$ & HAI & 16,1 & Araujo et al. (1984) [12] \\
\hline MG & IFI & 87 & Chiari, Lima \& Antunes (1985) [45] \\
\hline MG & IFI & $\begin{array}{c}36,1 \% \text { caprino leiteiro } \\
11,4 \% \text { corte } \\
62,9 \% \text { alimentação e renda } \\
\text { familiar }\end{array}$ & Machado \& Lima (1987) [128] \\
\hline MG & IFI & $\begin{array}{l}\text { 92,4\% área peri-urbana Belo } \\
\text { Horizonte } \\
\text { 79\% área urbana Pedra Azul } \\
32 \% \text { área rural Pedra Azul }\end{array}$ & Chiari et al. (1987) [46] \\
\hline RS & HAI & 23 & Braccini et al. (1992) [22] \\
\hline RJ & IFI & 15,84 & Serra-Freire, Norberg \& Gazeta (1994) [189] \\
\hline PR & IFI & 30,71 & Sella et al. (1994) [188] \\
\hline MG & $\begin{array}{l}\text { HAI } \\
\text { IFI }\end{array}$ & $\begin{array}{c}11,9 \\
10\end{array}$ & Figueiredo, Cabral \& Silva (1997) [82] \\
\hline $\mathrm{PB}$ & IFI & 26,8 & Alves et al. (1997) [5] \\
\hline BA & $\mathrm{AL}$ & 28,93 & Gondim et al. (1999) [102] \\
\hline SP & IFI & 14,47 & Mainardi et al. (2000) [131] \\
\hline SP & ELISA & 17 & Meireles (2001) [138] \\
\hline SP & $\begin{array}{c}\text { IFI } \\
\text { MAD }\end{array}$ & $\begin{array}{c}8 \\
11\end{array}$ & Silva, Cutolo \& Langoni (2002) [191] \\
\hline PE & IFI & 10,33 & Silva, Cunha \& Meireles (2003) [190] \\
\hline RS & $\begin{array}{l}\text { HAI } \\
\text { IFI }\end{array}$ & $\begin{array}{c}19,4 \\
30\end{array}$ & Maciel \& Araújo (2004) [129] \\
\hline SP & IFI & 28,7 & Figliuolo (2004) [81] \\
\hline BA & IFI & 11,53 & Uzêda et al. (2004) [72] \\
\hline MG & $\begin{array}{c}\text { HAI } \\
\text { ELISA }\end{array}$ & $\begin{array}{l}45,8 \\
42,8\end{array}$ & Carneiro (2006) [37] \\
\hline $\mathrm{PB}$ & IFI & 24,5 & Faria et al. (2007) [75] \\
\hline $\mathrm{RN}$ & IFI & 17,1 & Lima et al. (2008) [124] \\
\hline $\mathrm{CE}$ & ELISA & 25,1 & Cavalcante et al. (2008) [40] \\
\hline
\end{tabular}




\section{Toxoplasmose em caprinos}

$\mathrm{O}$ primeiro relato de toxoplasmose em caprinos foi feito por Feldman \& Miller, em 1956, nos Estados Unidos da América [77].

Os caprinos se contaminam ingerindo oocistos nas pastagens ou através de vetores mecânicos. Nas criações de caprinos, a presença da toxoplasmose causa perdas econômicas por abortos e por mortes neonatais [26]. Após inoculação experimental, foi observado hipertermia, anorexia e letargia em caprinos com mais de 12 meses de idade [184].
Perdas reprodutivas em um rebanho de caprinos foram associadas à presença de anticorpos para $T$. gondii e lesões. Nesse rebanho, foi observado também linfonodos mesentéricos pálidos e aumentados, pulmões firmes, intercalando áreas claras e vermelhas, além de pneumonia, encefalite, meningoencefalite e mielite não supurativa, linfadenite necrosante, nefrite intesticial e hepatite periportal linfoplasmocitárias [171]. Em outro rebanho só 3 de 39 fêmeas analisadas com problemas reprodutivos apresentaram anticorpos para T. gondii [124].

Tabela 4. Prevalência de anticorpos para Toxoplasma gondii em ovinos, no Brasil.

\begin{tabular}{|c|c|c|c|}
\hline ESTADO & TESTE & PREVALÊNCIA & REFERÊNCIAS \\
\hline RS & HAI & 23 & Amaral, Santos \& Rebouças (1978) [7] \\
\hline RS & SF & 39 & Larsson et al. (1980) [119] \\
\hline RS & IFI & 9,8 & Silva, Costa \& Souza (1980) [204] \\
\hline RS & IFI & 12,8 & Silva et al. (1981) [203] \\
\hline RS & HAI & $\begin{array}{c}\text { Uruguaiana } 18,2 \\
\text { Marau } 18,6\end{array}$ & Zonta et al. (1987) [231] \\
\hline RS & $\mathrm{AL}$ & 10 & Martins \& Hancock (1991) [135] \\
\hline RS & HAI & 35,2 & Braccini et al. (1992) [22] \\
\hline SP & $\begin{array}{l}\text { HAI } \\
\text { IFI }\end{array}$ & $\begin{array}{l}17,5 \\
22,5\end{array}$ & Oliveira Sequeira et al. (1993) [165] \\
\hline RS & IFI & 47,83 & Freire et al. (1995) [85] \\
\hline RS & $\begin{array}{l}\text { HAI } \\
\text { IFI }\end{array}$ & $\begin{array}{l}22 \\
24\end{array}$ & Ulon (1996) [218] \\
\hline SP & $\begin{array}{l}\text { HAI } \\
\text { IFI }\end{array}$ & $\begin{array}{c}30,4 \\
55,11\end{array}$ & Rosa et al. (1997) [182] \\
\hline RS & $\mathrm{AL}$ & 44 & Martins et al. (1998) [136] \\
\hline BA & $\mathrm{AL}$ & 18,75 & Gondim et al. (1999) [102] \\
\hline $\begin{array}{l}\text { PR } \\
\text { SP }\end{array}$ & IFI & 51,8 & Garcia et al. (1999) [97] \\
\hline SP & ELISA & 31 & Meireles (2001) [138] \\
\hline SP & IFI & 7,7 & Silva \& Langoni (2001) [193] \\
\hline SP & $\begin{array}{l}\text { IFI } \\
\text { MAD }\end{array}$ & $\begin{array}{l}23 \\
27\end{array}$ & Silva, Cutolo \& Langoni (2002) [191] \\
\hline $\mathrm{PE}$ & IFI & 35,3 & Silva, Cunha \& Meireles (2003) [190] \\
\hline PR & IFI & 54,3 & Ogawa et al. (2003) [162] \\
\hline RS & $\begin{array}{l}\text { HAI } \\
\text { IFI }\end{array}$ & $\begin{array}{l}13,6 \\
15,2\end{array}$ & Escopelli (2004) [74] \\
\hline SP & IFI & 34,7 & Figliuolo et al. (2004) [80] \\
\hline $\mathrm{DF}$ & IFI & 38,22 & Ueno (2005) [217] \\
\hline MG & $\begin{array}{c}\text { IFI } \\
\text { ELISA }\end{array}$ & $\begin{array}{l}43,2 \\
31,2\end{array}$ & Carneiro (2006) [37] \\
\hline RS & $\begin{array}{l}\text { HAI } \\
\text { IFI }\end{array}$ & $\begin{array}{l}19,5 \\
44,8\end{array}$ & Silva \& Rue (2006) [199] \\
\hline PR & IFI & 7 & Moura et al. (2007) [148] \\
\hline PR & IFI & 51,5 & Romanelli et al. (2007) [180] \\
\hline
\end{tabular}




\section{Toxoplasmose em ovinos}

A toxoplasmose ovina foi relatada pela primeira vez em 1942, por Olafson \& Monlux, nos EUA [218].

Em Jaboticabal, oito ovinos foram inoculados com T. gondii e apresentaram os seguintes sinais: hipertermia, distúrbios respiratórios (dispnéia, tosse e corrimento nasal), anorexia, diarréia, tremores musculares e prostração [133].

Em Rosário do Sul, foi investigada a possibilidade de transmissão congênita do $T$. gondii em cordeiros, pela detecção de anti-corpos IgG e IgM em soros de cordeiros e de suas mães, que não apresentavam sinais clínicos. Foram utilizadas as técnicas de HAI e IFI, e pela interpretação dos resultados da sorologia, foi constatado que $18,33 \%$ dos cordeiros que apresentaram títulos na primeira coleta tiveram um decréscimo ou negativação da resposta imunológica na segunda coleta, indicando transferência passiva de anticorpos. Apenas 3,33\% dos cordeiros, filhos de fêmeas que indicavam infecção recente, apresentaram títulos crescentes [198].

\section{Toxoplasmose em bovídeos}

A doença natural em bovídeos foi diagnosticada pela primeira vez por Houersdorf \& Holtz em 1952 [163].

Foram inoculados seis bovinos (três Bos indicus e três Bos taurus) e três búfalos (Bubalus bubalis) com oocistos de T. gondii. Todos os animais produziram anticorpos para $T$. gondii a partir do quinto dia, detectados pela IFI, sendo os títulos mais elevados em taurinos [163].

Tabela 5. Prevalência de anticorpos para Toxoplasma gondii em bovídeos, no Brasil

\begin{tabular}{|c|c|c|c|}
\hline ESTADO & TESTE & PREVALÊNCIA & REFERÊNCIAS \\
\hline MG & IFI & 12 & Costa \& Costa (1978) [50] \\
\hline SP & IFI & 32,3 & Costa et al. (1978) [51] \\
\hline $\mathrm{AM}$ & HAI & 60 & Ferraroni \& Marzochi (1978)* \\
\hline $\mathrm{AM}$ & HAI & 12 & Ferraroni et al. $(1980)^{*}$ \\
\hline RS & HAI & 3,4 & Silva et al. (1982/83) [200] \\
\hline $\mathrm{RS}$ & HAI & 5,4 & Chaplin et al. (1984) [44] \\
\hline MG & IFI & 9 & Passos, Lima \& Figueiredo (1984) [168] \\
\hline $\mathrm{RS}$ & HAI & 6,7 & Braccini et al. (1992) [22] \\
\hline PR & IFI & 32,34 & Marana et al. (1994) [132] \\
\hline $\mathrm{RS}$ & HAI & 29,13 & Adamy et al. (1995) [3] \\
\hline $\mathrm{RS}$ & HAI & 38,78 & Lazzarotto et al. (1997) [120] \\
\hline MS & HAI & 4,29 & Araújo, Carvalho, Balbuena (1998) [14] \\
\hline BA & $\mathrm{AL}$ & $\begin{array}{l}\text { Bovinos: } 1,03 \\
\text { Búfalos: } 3,85\end{array}$ & Gondim et al. (1999) [102] \\
\hline PR & IFI & 25,8 & Garcia (1999) [97] \\
\hline $\begin{array}{l}\text { SP } \\
\text { MG }\end{array}$ & IFI & 49,17 & Costa et al. (2001) [53] \\
\hline $\mathrm{SP}$ & IFI & 3,2 & Fujii et al. (2001) [92] \\
\hline $\mathrm{SP}$ & ELISA & 11 & Meireles (2001) [138] \\
\hline $\mathrm{SP}$ & IFI & 49,9 & Souza et al. (2001) [207] \\
\hline PR & IFI & 55,71 & Carleti et al. (2002) [35] \\
\hline PR & IFI & 41,4 & Daguer et al. (2004) [57] \\
\hline PR & IFI & 26 & Ogawa et al. (2005) [161] \\
\hline BA & IFI & 9,8 & Oliveira et al. (2005) [164] \\
\hline
\end{tabular}

* apud Vidotto (1992) [225] **apud Frenkel (1997) [87] 
Tabela 6. Prevalência de anticorpos para Toxoplasma gondii em eqüinos, no Brasil

\begin{tabular}{cccl}
\hline ESTADO & TESTE & PREVALÊNCIA & \multicolumn{1}{c}{ REFERÊNCIAS } \\
\hline RS & HAI & 8 & Silva et al. (1981) [201] \\
MS & IFI & 32,80 & Laranjeira, Ishizuka \& Hyakutaki (1985) [118] \\
SP & IFI & 24,8 & Costa et al. (1986) \\
RS & HAI & 2 & Braccini et al. (1992) [22] \\
RS & HAI & 59 & Barcelos et al. (1997) [18] \\
RJ & IFI & 4,42 & Gazêta et al. (1997) [98] \\
SP, PR, & IFI & 31,55 & Vidotto et al. (1997) [227] \\
MS, MT & & 12,1 & \\
PR & IFI & 1,5 & Garcia et al. (1999) [97] \\
BA & IFI/MAD & Mendonça et al. (2001) [142] \\
PR & IFI & 28,46 & Navarro et al. (2002) [151] \\
PR & IFI & 36,36 & Carleti et al. (1997) [120] \\
SP & IFI & 47,05 & Villalobos et al. (2005) [224] \\
MG & IFI & 12,82 & Naves et al. (1999) [154] \\
\hline
\end{tabular}

\section{Toxoplasmose em equinos}

Os eqüinos são animais herbívoros, e a infecção nesta espécie dá-se, provavelmente, ingerindo ou inalando oocistos presentes em alimentos, em feno e em cama contaminados com oocistos [192].

Foram observados sinais clínicos em 52 equinos da raça Psi, que foram positivos para T. gondii, pelo teste d e Sabin-Feldman. Os eqüinos apresentavam incoordenação motora (24 animais), história de pelo menos um aborto (23 animais) e irritabilidade excessiva (5 animais) [130]. Em uma inoculação experimental de éguas prenhes negativas para $T$. gondii, com oocistos deste parasito, foram rela-tados sinais clínicos de hipertermia, perda de apetite, prostração, diarréia, secreção ocular mucosa e corrimento nasal seroso [134].

\section{Toxoplasmose em aves}

A toxoplasmose em aves, no Brasil, foi relatada em 1955, em um lote de frangos que tenham de 2 a 6 meses de idade, com mortalidade de 50\% [160].

Em frangos de corte, foi observado seis dias pós-inoculação de oocistos, diarréia esverdeada com duração de uma semana, e uma ave com apatia morreu após sintoma de dificuldade respiratória. $\mathrm{Na}$ necrópsia, foram observados esplenomegalia e coração pálido [139]. Codornas inoculadas com taquizoítos de T. gondii apresentaram esplenomegalia, hepatomegalia e hipertrofia pulmonar [4].

\section{Toxoplasmose em suínos}

A toxoplasmose suína natural foi diagnosticada pela primeira vez nos Estados Unidos por

Tabela 7. Prevalência de anticorpos para Toxoplasma gondii em aves, no Brasil.

\begin{tabular}{cccl}
\hline ESTADO & TESTE & PREVALÊNCIA & \multicolumn{1}{c}{ REFERÊNCIAS } \\
\hline AM & HAI & 41,18 & Ferraroni \& Marzochi (1978)* \\
RS & HAI & 2,8 & Araújo et al. (1989) [11] \\
RS & HAI & 30,32 & Barcelos et al. (1997) [19] \\
PR & IFI & 10,3 & Garcia et al. (2000) [94] \\
PR & MAT & 40 & Dubey et al. (2003) [70] \\
* apud Vidotto (1992) [225] & &
\end{tabular}


Tabela 8. Freqüência de anticorpos para T. gondii em soros de suínos no Brasil.

\begin{tabular}{|c|c|c|c|}
\hline ESTADO & TESTE & FREQUÊNCIA & REFERÊNCIAS \\
\hline SP e RS & HAI & $22,8 \%$ & Amaral, Santos e Rebouças (1975) [6] \\
\hline MG & IFI & $29,9 \%$ & Schenk, Lima \& Viana (1976) [187] \\
\hline SP & IFI & $22,5 \%$ & Correa, Salata \& Oliveira (1978) [49] \\
\hline SP & HAI & $24,68 \%$ & Santos, Amaral \& Rebouças (1978) [186] \\
\hline SP & IFI & $32,8 \%$ & Ishizuka (1978) [109] \\
\hline SP & IFI & $\begin{array}{c}\text { Leitões } 52,17 \\
\text { Crescimento } 48,83 \\
\text { Fêmeas } 45,83 \\
\text { Terminação } 45,40\end{array}$ & Vasconcelos, Costa \& Avila (1979) [223] \\
\hline $\mathrm{RS}$ & HAI & $7,2 \%$ & Silva et al. (1981) [202] \\
\hline $\mathrm{RS}$ & HAI & $7,4 \%$ & Chaplin \& Silva (1984) [41] \\
\hline MG & IFI & $33,4 \%$ & Passos \& Figueiredo (1984) [167] \\
\hline MG & HAI & $\begin{array}{c}\text { Intensivo } 54 \% \\
\text { Semi-intensivo } 49,2 \% \\
\text { Intensivo } 46 \% \\
\text { Semi-intensivo } 42,7 \%\end{array}$ & D'angelino \& Ishizuka (1968) [58] \\
\hline PR & IFI & $34,62 \%$ & Vidotto et al. (1986) [228] \\
\hline $\mathrm{SC}$ & HAI & $1,16 \%$ & Wentz, Sobestiansky \& Chaplin (1988) [230] \\
\hline PR & IFI & $37,84 \%$ & Vidotto et al. (1990) [229] \\
\hline MG & IFI & $90,4 \%$ & Guimarães et al. (1992) [105] \\
\hline RS & HAI & $18 \%$ & Grünspan et al. (1995) [104] \\
\hline RJ & $\begin{array}{l}\text { HAI } \\
\text { IFI }\end{array}$ & $\begin{array}{l}0,79 \% \\
0,88 \%\end{array}$ & Souza (1995) [210] \\
\hline GO & HAI & $27,74 \%$ & Matos et al. (1999) [137] \\
\hline RS & $\begin{array}{c}\text { IFI } \\
\text { ELISA }\end{array}$ & $\begin{array}{l}7,3 \% \\
9,5 \%\end{array}$ & Araujo (1999) [10] \\
\hline $\mathrm{PE}$ & & 54,17 & Porto et al. (1999) [175] \\
\hline PR & IFI & $24 \%$ & Garcia et al. (1999) [97] \\
\hline SP & ELISA & 9,57 & Suárez, Andre Jr., Galisteo (1999) [213] \\
\hline $\mathrm{SP}$ & ELISA & 8,5 & Meireles (2001) [138] \\
\hline PR & IFI & $15,35 \%$ & Tsutsui et al. (2001) [216] \\
\hline PR & IFI & 42,85 & Carletti et al. (2002) [35] \\
\hline RS & $\begin{array}{l}\text { HAI } \\
\text { IFI }\end{array}$ & $\begin{array}{c}20 \\
33,75\end{array}$ & Fialho \& Araújo (2003) [79] \\
\hline PR & IFI & 4 & Carletti et al. (2005) [36] \\
\hline $\mathrm{SP} / \mathrm{PE}$ & $\begin{array}{c}\text { IFI } \\
\text { MAD }\end{array}$ & $\begin{array}{l}2,11 \\
1,32\end{array}$ & Caporali et al. (2005) [33] \\
\hline $\mathrm{RS}$ & $\begin{array}{l}\text { HAI } \\
\text { IFI }\end{array}$ & $\begin{array}{c}9,2 \\
13,9\end{array}$ & Pereira (2005) [170] \\
\hline RO & $\begin{array}{l}\text { MAT } \\
\text { IFI }\end{array}$ & $\begin{array}{l}37,5 \\
43,7\end{array}$ & Cavalcante et al. (2006) [38] \\
\hline SP & IFI & 8,5 & Lima et al. (2007) [123] \\
\hline MG/SP & MAD & 0 & Pezerico et al. (2007) [172] \\
\hline PR & IFI & 8,54 & Moura et al. (2007) [148] \\
\hline PR & IFI & 25,5 & Millar et al. (2008) [143] \\
\hline
\end{tabular}


Farrel et al. (1952), em rebanho com mortalidade em todas as faixas etárias [76]. No Brasil, foi diagnosticada pela primeira vez por Silva (1959), em Minas Gerais, pelo encontro dos protozoários nos pulmões, coração, fígado e linfonodo mesentérico, em um suíno de 28 dias de idade, de uma leitegada, da qual dois já haviam morrido nos primeiros dias de vida [197].

Os suínos adquirem a toxoplasmose principalmente pela ingestão de água e de ração contaminadas com fezes de felinos. A maioria das infecções são subclínicas, ocorrendo doença clínica em neo-natos e leitões jovens e a ocorrência de aborto [147]. Foi relatada uma elevada taxa de fetos mumificados em uma granja, e verificado $100 \%$ de positivos para T.gondii, no soro das 30 matrizes pesquisadas [47]. Porcas inoculadas com taquizoítos de $T$. gondii durante a gestação abortaram ou apresentaram fetos mumificados e leitões aparentemente normais [226]. Nos suínos adultos, os sinais incluem febre, cegueira, fraqueza e queda no ganho de peso [147].

Além dos estudos sorológicos, muitos autores têm realizado pesquisa nas carnes e vísceras ou em embutidos suínos. Por inoculação de amostras de lingüiça em camundongos foi encontrado $8,7 \%$ de positividade [60]. Em estudo de cérebros foi observado 50\% de positivos [84]. Suínos inoculados com T. gondii após abate apresentaram $100 \%$ de positividade em cortes de carnes [215].

\section{DIAGNÓSTICO}

O diagnóstico laboratorial pode ser realizado pela demonstração do coccídio (parasitológico) ou por métodos indiretos (imunológico) e por biologia molecular.

A pesquisa de oocistos pode ser realizada nas fezes de felídeos, por método de centrifugoflutuação com solução de Sheather, no período de eliminação ativa do ciclo enteroepitelial, que dura de uma a duas semanas. Mas, como a maioria dos gatos são assintomáticos, durante esse estágio, normalmente o exame fecal não é um bom método de diagnóstico [214].

A pesquisa direta do $T$. gondii pode ser feita a partir de diversos componentes orgânicos como sangue, líquido cefalorraquidiano, saliva, leite, escarro, medula óssea, cortes de placenta, além de conteúdos de infiltrados cutâneos, do baço, fígado, músculos e linfonodos [147,157]. O material obtido pode ser utilizado para fazer diagnóstico por inoculação em camundongo ou histopatológico [157].

O diagnóstico imunológico é feito pela presença de anticorpos específicos, através de sorologia. Diversas provas imunológicas têm sido utilizadas na avaliação da infecção toxoplásmica como reações de hemaglutinação (HAI), imunofluorescência indireta, aglutinação por imunoabsorção (ISAGA), ensaio imunoenzimático (ELISA) [54].

O diagnóstico sorológico da toxoplasmose deve ser corretamente interpretado para diferenciar infecção de doença. Se a intenção é avaliar a imunidade do paciente, os testes sorológicos que detectam anticorpos da classe IgG são suficientes [31]. Mas, para o diagnóstico da doença é preciso associar sintomas clínicos com a presença de variação de títulos de $\operatorname{IgG}$ (elevação ou redução), num período de duas a três semanas, ou a presença de anticorpos $\operatorname{IgM}$ [157]. Estima-se que um terço ou mais da população humana possua anticorpos para T. gondii [146]. No recém-nascido, anticorpos da classe $\mathrm{IgG}$, podem ser anticorpos maternos, que, na criança não infectada, podem permanecer na circulação ao longo do primeiro ano de vida. É necessário realizar a IgM ou IgA, pois não atravessam a placenta e então, quando presentes, indicam a produção pelo próprio feto, devido à infecção intrauterina [54].

Devido aos felinos usualmente não desenvolverem anticorpos durante o período de eliminação dos oocistos, o exame sorológico não nos concede uma informação útil sobre a transmissibilidade da toxoplasmose nesta espécie. Um gato sorolo-gicamente positivo (imune) apenas indica que ele provavelmente eliminou oocistos e, então, oferece menos perigo na transmissão do que um gato negativo, embora, gatos imunes possam vir, mesmo que raramente, a eliminar oocistos numa nova infecção, sendo apropriado precauções ao lidar com fezes de felinos [66].

\section{TRATAMENTO}

O tratamento mais utilizado é a associação de sulfadiazina com a pirimetamina, mas estão disponíveis outras sulfonamidas (sulfamerazina, sulfametazina e sulfapirazina), além de clindamicina, dapsona e atovaquona [157]. 
Crianças com diagnóstico de toxoplasmose devem ser tratadas durante o primeiro ano de vida, ou até que se exclua a infecção aguda. Já as crianças suspeitas, devem ser acompanhadas por sorologia, até a exclusão da infecção [9]. O esquema recomendado é a pirimetamina $2 \mathrm{mg} / \mathrm{Kg} / \mathrm{dia}$, via oral, nos primeiros dois dias, seguido por $1 \mathrm{mg} / \mathrm{Kg} / \mathrm{dia}$, por dois ou seis meses, e após, $1 \mathrm{mg} / \mathrm{Kg} /$ dia três vezes por semana; associada à sulfadiazina na dose de $100 \mathrm{mg} /$ $\mathrm{Kg} / \mathrm{dia}$, via oral, de 12/12 horas. Para proteger a medula do efeito tóxico da pirimetamina, deve ser utilizado de 10 a $20 \mathrm{mg} /$ dia do ácido folínico, via oral, três vezes por semana. Corticosteróides na dose $1 \mathrm{mg} /$ $\mathrm{Kg} / \mathrm{dia}$, via oral de 12/12 horas, têm sido recomendado nos recém-nascidos com grave comprometimento do Sistema Nervoso Central, quando a proteína do líquor for inferior a $1 \mathrm{~g} / \mathrm{dl}$ ou quando for diagnosticada coriorretinite [61].

Em uma revisão das alternativas terapêuticas utilizadas para cães, foi relatado o uso de sulfadiazina, pirimetamina, clindamicina, fosfato de clindamicina e cloreto de clindamicina [23].

\section{PREVENÇÃO E CONTROLE}

Para a população humana, a infecção por $T$. gondii é relacionada ao consumo de carne mal cozida contaminada com cistos desse parasito, por ingestão de alimentos ou água contaminados com oocistos prove-nientes de fezes de felídeos, infecção congênita [157] e provavelmente por infecção transmamária [166].

Uma das formas de reduzir a infecção humana pelo T. gondii é destruir os cistos da carne cozinhando-a, até uma temperatura de $67^{\circ} \mathrm{C}$ [68], ou $60^{\circ} \mathrm{C}$ por $20^{\prime}$, com garantia de que o calor penetre igualmente no alimento [155]. Foi observado que a utilização do sal, na preparação de lingüiça suína mostrouse eficaz em 48 horas [152]. O congelamento de 18 a $24 \mathrm{~h}$, pode ser considerado um meio de destruição dos cistos. [179]. Devemos lavar bem as mãos e os utensílios, após mexermos em carne crua para não ingerir formas infectantes, assim como lavá-las após contato com fezes de gato, ou após mexer na terra que pode estar contaminada com oocistos. Nunca devemos beber leite não pasteurizado [83]. Também é necessário cobrir o tanque de areia das crianças, quando não estiver em uso. A caixa dos felinos deve ser limpa diariamente para evitar contato com oocistos esporulados e o destino adequado a essas fezes é a incineração. Devemos alimentar os gatos com ração e combater ratos e camundongos, além de fazer o controle da população felina [157].

A infecção congênita ocorre quando a mulher adquire a primoinfecção pelo $T$. gondii durante a gestação, e, quanto mais precoce isso ocorre, mais severos serão os sinais clínicos [9]. Pode ocorrer aborto, nascimento de crianças com a tétrade de Sabin (macro ou microcefalia, coriorretinite, calcificações cerebrais e retardo mental), déficit intelectual, retinocoroidite bilateral, estrabismo ou nascimento de crianças aparentemente normais, que apresentam cistos em estado de latente [157], vindo a manifestar a doença mais tardia-mente, na primeira ou na segunda década de vida, e isso pode ser devido às modificações hormonais [174]. Alterações oculares estão entre as mais frequentemente observadas por toxoplasmose [95, 205]. As mulheres grávidas soronegativas para T. gondii não devem manter contato direto com fezes de gatos, solo ou ingerir carne mal passada. Devem beber água tratada e fazer sorologia antes da gravidez e, pelo menos trimestralmente, durante a gestação [9].

A infecção aguda em adultos pode acarretar alteração ganglionar, febre, um leve resfriado ou adenopatia e hepatoesplenomegalia [54]. A toxoplasmose adquirida pelo paciente imunodeprimido frequentemente aparece como doença do Sistema Nervoso Central (encefalite) e retinite [157,205]. Os imunodeprimidos com sorologia negativa também devem fazer exames periódicos diagnosticando a infecção logo no início [174].

Para diminuir a infecção nos animais de criação, principalmente nos ovinos, caprinos e suínos, o número de gatos nas criações rurais deve ser reduzido [229]. As membranas fetais e fetos abortados devem ser removidos por pessoas usando luvas e enterradas ou incinerados, para prevenir infecção em gatos e em outros animais da criação [65].

Deve-se fazer o controle de artrópodes (moscas e baratas), já que eles podem ser disseminadores mecânicos de oocistos [174].

\section{IMUNOTERAPIA}

Não existe ainda vacina para toxoplasmose humana. Uma vacina foi testada com bom nível de proteção contra a emissão de oocistos toxoplásmicos 
pelos gatos, utilizando a cepa T-263. Uma outra vacina induziu imunidade em gatos, também na emissão de oocistos, após administração oral de cistos e bradizoítos da mesma cepa e, posteriormente, no desafio com cistos de T256 [89].

Muitos autores têm testado modelos experimentais em roedores, utilizando cepas diferentes como imunizantes e desafio para testar a imunidade para toxoplasmose [71,73,90,91]. Suínos, também têm sido utilizados para testar vacinas $[86,93]$.
Existe uma vacina comercial para ovinos (Toxovax ${ }^{\circledR}$ ), que reduz o aborto e é produzida com taquizoítos da cepa acistogênica S48 [28].

\section{CONCLUSÕES}

Toxoplasma gondii é um parasito de ampla distribuição e alta prevalência no Brasil. A toxoplasmose é uma doença importante pelos danos reprodutivos em várias espécies de animais e principalmente nos humanos.

\section{REFERÊNCIAS}

1 Abreu C.B., Navarro I.T., Reis A.C. F., Souza M.S.B., Machado R., Marana E.R.M., Prudêncio L.B., Mattos M.R. \& Tsutsui V.S. 2002. Toxoplasmose ocular em cães jovens inoculados com Toxoplasma gondii. Ciência Rural. 32: 807-812.

2 Abreu C.B., Navarro I.T., Balarin M.R.S., BracarenseA.P.F.R.L., Marana E.R.M., Trapp S.M., Fuginaka C.A., Prudêncio L.B., Matos M.R. \& Tsutsui V.S. 2001. Aspectos clínicos, patológicos e sorológicos da toxoplasmose experimental em cães jovens. Semina: Ciências Agrárias. 22: 123-130.

3 Adamy M., Moraes R.Q., Michelon E., Leite C.C., Colombo F.H., Ribas H.O., Cenci A., Santos M., Pit G., Bento L.S., Muller G., Langohr I., Flores M.L., Lazarotto J.J., Noal S.A. \& Lagaggio V.R.A. 1995. Estudos preliminares sobre toxoplasmose em gado leiteiro. In: II Jornada Integrada de Pesquisa, Extensão e Ensino da Universidade Federal de Santa Maria-RS (Santa Maria, Brasil). p. 332.

4 Albuquerque G.R., Munhoz A.D., Oliveira F.C.R., Pinto A.R.S. \& Lopes C.W.G. 2002. Alterações patológicas na infecção experimental de codornas (Coturnix japonica) com taquizoítos de Toxoplasma gondii (Apicomplexa: Toxoplasmatinae). Revista Brasileira de Parasitologia Veterinária. 11: 43-46.

5 Alves C.J., Vasconcellos S.A., Navarro I.T. \& Barbosa C.S. 1997. Avaliação dos níveis de aglutininas anti-Toxoplasma em soros de caprinos de cinco centros de criação do nordeste do Brasil. Revista Brasileira de Ciência Veterinária. 14: 7577.

6 Amaral V.D.O., Santos S.M. \& Rebouças M.M. 1975. Estudos preliminares sobre a prevalência de anticorpos antitoxoplasma, por hemaglutinação, em soros de suínos provenientes dos Estados de São Paulo e Rio Grande do Sul, Brasil. O Biológico. 41: $105-107$.

7 Amaral V.D.O., Santos S.M. \& Rebouças M.M. 1978. Sobre a prevalência de anticorpos antitoxoplasma em soros de caprinos e ovinos procedente, respectivamente dos estados da Bahia e Rio Grande do Sul, BR. O Biológico. 44: 331-340.

8 Amato Neto V., Medeiros E.A.S., Levi G.C. \& Duarte M.I.S. 1995. Toxoplasmose. 4.ed. São Paulo: Sarvier, 154p.

9 Andrade G.M., Carvalho A.L., Nogueira M.G.S. \& Oréfice F. 2004. Toxoplasmose congênita - Orientação prática sobre prevenção e tratamento. Revista Médica de Minas Gerais. 14: 85-91.

10 Araujo F.A.P. 1999. Avaliação soroepidemiológica de anticorpos para Toxoplasma gondii Nicolle \& Manceaux, 1909 em soros de suínos (Sus scrofa) da região da Grande Erechim, RS - Brasil, detectados através das técnicas de imunofluorescência indireta de imunoenzimática. 125f. RJ. Tese (Doutorado em Biologia Parasitária) - Programa de Pós-Graduação em Biologia Parasitária, Instituto Oswaldo Cruz.

11 Araujo F.A.P., Silva N.R.S., Chaplin E.L. \& Bigatti L.E. 1989. Prevalência de anticorpos toxoplásmicos em frangos abatidos para consumo humano em Porto Alegre, Rio Grande do Sul. Arquivos da Faculdade de Veterinária da UFRGS. 17: 23-28.

12 Araujo F.A.P., Silva N.R.S., Chaplin E.L. \& Santos E.B. 1984. Prevalência de anticorpos toxoplásmicos em soros de caprinos da Região da Grande Porto Alegre/RS. Arquivos da Faculdade de Veterinária da UFRGS. 12: 35-40.

13 Araujo F.A.P., Silva N.R.S., Olicheski A.T., Beck C., Rodrigues R.J.D. \& Fialho C.G. 2003. Anticorpos para Toxoplasma gondii em soros de gatos internados no Hospital de Clínicas Veterinárias da UFRGS, Porto Alegre, RS, Brasil, detectados através da técnica de hemaglutinação indireta. Acta Scientiae Veterinariae. 31: 89-92.

14 Araujo F.R., Carvalho C.M.E. \& Balbuena C.B. 1998. Levantamento sorológico para Toxoplasma gondii em bovinos de corte do estado do Mato Grosso do Sul, Brasil. Revista Brasileira de Medicina Veterinária. 20: 201-203. 
15 Araujo W.N., Silva A.V. \& Langoni H. 1998. Toxoplasmose: uma zoonose - realidades e riscos. Cães e Gatos. 79: 20-27.

16 Azevedo S.S., Batista C.S.A., Vasconcellos S.A., Aguiar D.M., Ragozo A.M.A., Rodrigues A.A.R., Alves C.J. \& Gennari S.M. 2005. Seroepidemiology of Toxoplasma gondii and Neospora caninum in dogs from the State of Paraíba, Northeast region of Brazil. Research in Veterinary Science. 79: 51-56.

17 Barbosa M.V.F., Guimarães J.E., Almeida M.A.O., Gondim L.F.P. \& Regis G.B. 2003. Freqüência de anticorpos IgG anti-Toxoplasma gondii em soros de cães errantes da cidade de Salvador-Bahia, Brasil. Brazilian Journal of Veterinary Research and Animal Science. 40: 457-465.

18 Barcelos A.S., Lagaggio V.R.A., Cenci A., Colombo F.H., Katzer L.H. \& Noal S.A. 1997. Pesquisa de anticorpos antiToxoplasma gondii em equinos de Uruguaiana-RS-Brasil. In: IV Jornada Integrada de Pesquisa, Extensão e Ensino da Universidade Federal de Santa Maria-RS (Santa Maria-RS). p.565.

19 Barcelos A.S., Miolo J.R., Katzer L.H., Flores M.L. \& Lagaggio V.R.A. 1997. Hemaglutinação para toxoplasmose em aves domésticas do município de Santa Maria/RS. In: IV Jornada Integrada de Pesquisa, Extensão e Ensino da Universidade Federal de Santa Maria-RS (Santa Maria-RS). p.564.

20 Blood D.C. \& Radostits O.M. 1991. Clínica Veterinária. 7.ed. Rio de Janeiro: Guanabara Koogan, 1263p.

21 Bonametti A.M., Passos J.N., Silva E.M.K. \& Bortoliero A.L. 1997. Surto de toxoplasmose aguda transmitida através da ingestão de carne crua de gado ovino. Revista Sociedade Brasileira de Medicina Tropical.30: 21-25.

22 Braccini G.L., Chaplin E.L., Stobe N.S., Araújo F.A.P. \& Santos N.R. 1992. Resultados de exames laboratoriais realizados no setor de protozoologia da Faculdade de Veterinária da UFRGS, Porto Alegre, nos anos de 1986 a 1990. Arquivos da Faculdade Veterinária da UFRGS. 20: 134-149.

23 Bresciani K.D.S., Costa A.J., Navarro I.T., Toniollo G.H., Sakamoto C.A.M., Arantes T.P. \& Gennari S.M. 2008. Toxoplasmose canina: aspectos clinicos e patológicos. Semina: Ciências Agrárias. 29: 189-202.

24 Bresciani K.D.S., Toniollo G.H., Costa A.J., Sabatini G.A. \& Moraes F.R. 2001. Clinical parasitological and obstetric observation in pregnants bitches with experimental toxoplasmosis. Ciência Rural. 31: 1039-1043.

25 Bresciani W.R., GennariS.M.,SerranoA.C.M., Rodrigues A.A.R., Ueno T., Franco L.G., PerriS.H.V. \&AmaranteA.F.T. 2007. Antibodies to Neospora caninum and Toxoplasma gondii in domestic cats from Brazil. Parasitology Research. 100: 281-285.

26 Breuning J. 2008. Toxoplasmose em caprinos. Caprinforma. Ano V: p.4.

27 Brito A.F., Souza L.C., Silva A.V. \& Langoni H. 2002. Epidemiological and serological aspects in canine toxoplasmosis in animals with nervous symptoms. Memórias do Instituto Oswaldo Cruz. 97: 31-35.

28 Buxton D.D., Thomson K.M., Maley S., Wright S. \& Bos H.J. 1993. Experimental challenger of sheep 18 monthos afther vaccination with a live (S48) Toxoplasma gondii vaccine. Veterinary Record. 25: 310-312.

29 Cabral D.D., Silva D.A.O., Mineo J.R., Ferreira F.A. \& Duran F.P. 1998. Frequency of anti-Toxoplasma gondii antibodies in apparently healthy dogs of the city of Uberlândia, MG. Revista Brasileira de Parasitologia Veterinária. 7: 87-90.

30 Camargo M.C.G.O., Mouriz E.S.M., D’auria S.R.N.D. \& Fraga G.M.D. 1998. Toxoplasmose em felinos do município de São Paulo - Brasil, 1993-1995. In: II Congresso Argentino de Zoonosis. Associación Argentina de Zoonosis. p.97.

31 Camargo M.E. 1996. Toxoplasmose: diagnóstico sorológico. Boletim Médico do Laboratório Bronstein, Porto Alegre. V: $4 \mathrm{p}$.

32 Cañón-Franco W.A., Bergamashi D.P., Richtzenhan L.J., Nogueira Y., Camargo L.M.A., Souza S.L.P. \& Gennari S.M. 2003. Evaluation of the performance of the modified direct agglutination test (MAT) for detection of Toxoplasma gondii antibodies in dogs. Brazilian Journal of Veterinary Research and Animal Science. 40: 452-456.

33 Caporali E.H.G., Silva A.V., Mendonça A.O. \& Langoni H. 2005. Comparação de métodos para determinação da prevalência de anticorpos anti-Toxoplasma gondii em suínos dos Estados de São Paulo e Pernambuco, Brasil. Arquivos de Ciências Veterinárias e Zoologia da UNIPAR. 8: 19-24.

34 Carini A. 1911. A infection spontanée du pigeon et du chien due au toxoplasma cuniculi. Bulletin de la Société de Pathologie Exotique. 4: 518-519.

35 Carletti R.T., ContenteA.P.A., Navarro I.T., Prudencio L.B., Tsutsui V.S., Marana E.R.M. \& Romão G.O. 2002. Surto de toxoplasmose em Santa Isabel do Ivaí - PR, Brasil: sorologia em animais domésticos. In: XXIX Congresso Brasileiro de Medicina Veterinária (Gramado-Brasil). p.60

36 Carletti R.T., Freire R.L., Shimada M.T., Ruffolo B.B., Begale L.P., Lopes F.M.R. \& Navarro I.T. 2005. Prevalência da infecção por Toxoplasma gondii em suínos abatidos no Estado do Paraná, Brasil. Semina: Ciências Agrárias. 26: 563-568. 
37 Carneiro A.C.A.V. 2006. Soroepidemiologia da toxoplasmose caprina e ovina no Estado de Minas Gerais. 116f. Belo Horizonte, MG. Dissertação (Mestrado em Epidemiologia das doenças infecciosas e parasitárias). Programa de PósGraduação em Parasitologia. Universidade Federal de Minas Gerais.

38 Cavalcante G.T., Aguiar D.M., Chiebao D., Dubey J.P., Ruiz V.L.A., Dias R.A., Camargo L.M.A., Labruna M.B. \& Gennari S.M. 2006. Seroprevalence of Toxoplasma gondii antibodies in cats and pigs from rural western Amazon, Brazil. Journal of Parasitology. 92: 863-864.

39 Cavalcante G.T., Aguiar D.M., Chiebao D.P., Meireles L.R., Andrade H,F., Camargo L.M.A., Labruna M.B., Ruiz V.L.A. \& Gennari S.M. 2004. Ocorrência de anticorpos anti-Toxoplasma gondii em humanos e animais domésticos da zona rural do Município de Monte Negro, Rondônia em cães. In: XIII Congresso Brasileiro de Parasitologia Veterinária (Ouro Preto, Brasil). p.217.

40 Cavalcante A.C.R., Carneiro M., Gouveia A.M.G., Pinheiro R.R. \& Vitor R.W.A. 2008. Risk factors for infection by Toxoplasma gondii in herds of goats in Ceará, Brazil. Arquivo Brasileiro de Medicina Veterinária e Zootecnia. 60: 36-41.

41 Chaplin E.L. \& Silva N.R.S. 1984. Toxoplasmose: medidas preventivas. Arquivos da Faculdade de Veterinária UFRGS. 12: 21-24.

42 Chaplin E.L., Silva N.R.S. \& Araujo F.A.P. 1991. Eliminação de oocistos tipo-toxoplasma por felinos naturalmente infectados. Arquivos da Faculdade de Veterinária UFRGS. 19: 77-81.

43 Chaplin E.L, Silva N.R.S., Kessler R.H. \& Souza S.G. 1980. Prevalência de cães sorologicamente positivos para Toxoplasma gondii (Nicolle \& Manceaux, 1908), internados no Hospital de Clínicas Veterinárias da Faculdade de Veterinária, UFRGS. Arquivos da Faculdade de Veterinária UFRGS. 8: 85-88.

44 Chaplin E.L., Silva N.R.S., Sebben J.C., Araújo F.A.P. \& Mendez L.D.V. 1984. Cadeia epidemiológica de toxoplasmose em Guaporé, RS, relacionando humanos e seus animais domésticos. Arquivos da Faculdade de Veterinária UFRGS. 12: 25-34.

45 Chiari C.A., Lima J.D. \& Antunes C.M.F. 1985. Reação de imunofluorescência indireta e de Sabin-Feldman na pesquisa de anticorpos anti-Toxoplasma gondii em soros de caprinos. Arquivo Brasileiro de Medicina Veterinária e Zootecnia. 37: 121-129.

46 Chiari C.A., Lima J.D., Lima W.S. \& Antunes C.M.F. 1987. Soroepidemiologia da Toxoplasmose caprina em Minas Gerais, Brasil. Arquivo Brasileiro de Medicina Veterinária e Zootecnia. 39: 587-609.

47 Ciacci-Zanella J.R., Silva R.A.M.S., Dambrós R., Zanella E.L. \& Bonassi C.A. 2001. Mumificação fetal em suínos associados à toxoplasmose. Embrapa suínos e Aves, Concórdia, (271): 1-4.

48 Coelho R.A., Kobayashi M. \& Carvalho Junior L.B. 2003. Prevalence of IgG antibodies specific to Toxoplasma gondii among blood donors in Recife, Northeast Brazil. Revista do Instituto de Medicina Tropical de São Paulo. 45: $229-231$.

49 Correa F.M.A., Salata E. \& Oliveira M.R. 1978. Toxoplasma gondii: diagnóstico, pela prova de imunofluorescência indireta em suínos no estado de São Paulo, Brasil. Arquivos do Instituto Biológico de São Paulo. 45: 209-212.

50 Costa A.J. \& Costa E.P. 1978. Frequência de bovinos reagentes à imunofluorescência indireta para Toxoplasma gondii em Poços de Caldas, MG, Brasil. Arquivos da Escola de Veterinária da UFMG. 30: 47-51.

51 Costa A.J., Ávila F.A., Kasai N., Paulillo A.C. Silva M.B. \& Galesco H. 1978. Anticorpos anti-toxoplasma em soros de bovinos do município de Jaboticabal; São Paulo, Brasil. Arquivos do Instituto Biológico de São Paulo. 45: $299-302$.

52 Costa A.J., Ishizuka M.M., Marques L.C., Vidotto O., Rocha U.F. \& Ikeda A. 1986. Toxoplasmosis frequency in equines from the north region of São Paulo State, Brazil. ARS Veterinária. 2: 75-79.

53 Costa G.H.N., Cabral D.D., Varandas N.P., Sobral E. A., Borges F.A. \& Castagnolli K.C. 2001. Frequência de anticorpos anti-Neospora caninum e anti-Toxoplasma gondii em soros de bovinos pertencentes aos estados de São Paulo e de Minas Gerais. Semina: Ciências Agrárias. 22: 61-66.

54 Costa T.L., Silva M.G., Rodrigues I.M.X., Barbaresco A.A., Avelino M.M. \& Castro A.M. 2007. Diagnóstico clínico e laboratorial da toxoplasmose. Newsla. 85: 88-104.

55 Coutinho S.G., Lobo R. \& Dutra G. 1982. Isolation of Toxoplasma from the soil during na outbreak of toxoplasmosis in a rural area in Brazil. Journal of Parasitology. 68: 866-868.

56 Cruz M.A. 2007. Soroprevalência anti-Toxoplasma gondii (NICOLLE \& MANCEAUX, 1908) em gatos domésticos (Felis catus - LINNAEUS, 1758) de Curitiba, Paraná. 87f. Dissertação (Mestrado em Ciências Veterinárias) - Programa de PósGraduação em Ciências Veterinárias, Universidade Federal do Paraná.

57 Daguer H., Vicente R.T., Costa T., Hamann M.P.V. \& Amendoeira M.R.R. 2004. Soroprevalência de anticorpos antiToxoplasma gondii em bovinos e funcionários de matadouros da microrregião de Pato Branco, Paraná, Brasil. Ciência Rural. 34: 1133-1137. 
58 D’angelino J.L. \& Ischizuka M.M. 1986. Toxoplasmose suína: Avaliação da prevalência de infecção toxoplásmica em rebanhos suínos pela prova de imunofluorescência indireta e hemaglutinação. Boletín de la Oficina Sanitaria Panamericana. 100: 634-647.

59 Dias R.A.F. \& Freire R.L. 2005. Surtos de toxoplasmose em seres humanos e animais. Semina: Ciências Agrárias. 6: 239248.

60 Dias R.A.F., Navarro I.T., Ruffolo B.B., Bugni F.M., Castro M.V. \& Freire R.L. 2005. Toxoplasma gondii in fresh pork sausage and soroprevalence in butchers from factiries in Londrina, Paraná State, Brazil. Revista do Instituto de Medicina Tropical de São Paulo. 47: 185-189.

61 Diniz E.M.A. \& Vaz F.A.C. 2003. Qual é a recomendação atual para o tratamento da toxoplasmose congênita. Revista da Associação Médica Brasileira. 49:10.

62 Domingues L.M., Machado R.Z., Costa A.J., Tinucci Costa M., Carvalho C.S., Costa A.J. \& Malheiros E.B. 1998. Canine toxoplasmosis: a comparative evaluation of the detectionof anti-Toxoplasma gondii antibodies by the indirect immunoenzymatic assay (ELISA) and the indirect immunofluorescence reaction (IIF). Revista Brasileira de Parasitologia Veterinária. 7: 79-85.

63 Dubey J.P. 1999. Recent advances in Neospora and neosporosis. Veterinary Parasitology. 84: 349-367.

64 Dubey J.P. 2005. Toxoplasmosis in cats and dogs. In: 30th World Small Animal Veterinary Association, México.[Fonte:http:/ /www.vin.com/proceeding/Proceeding.]

65 Dubey J.P. 1994. Toxoplasmosis. JAVMA. 205:1593-1598.

66 Dubey J.P. 1987. Toxoplasmosis. Veterinary Clinics of North America: Small Animal Practice. 17: 1389-1404.

67 Dubey J.P., Miller N.L. \& Frenkel J.K. 1970. Characterization of the new fecal form of Toxoplasma gondii. Journal of Parasitology. 56: 447-456.

68 Dubey J.P., Kotula A.W., Sharar A., Andrews C.D. \& Lindsay D.S. 1990. Effect of high temperature on infectivity of Toxoplasma gondii tissue cysts in pork. Journal of Parasitology. 76: 201-204.

69 Dubey J.P., Navarro I.T., Sreekumar C., Dahl E., Freire R.L., Kawabata H.H., Vianna M.C.B., Kwok O.C.H., Shen S.K., Thulliez P. \& Lehmann T. 2004. Toxoplasma gondii infections in cats from Paraná, Brazil: Seroprevalence, tissue distribution, and biologic and genetic characterization of isolates. Journal of Parasitology. 90: 721-726.

70 Dubey J.P., Navarro I.T., Graham D.H., Dahl E., Freire R.L., Prudêncio L.B., Sreekumar C., Vianna M.C. \& Lehmann T. 2003. Characterization of Toxoplasma gondii isolates from free range chickens from Paraná, Brazil. Veterinary Parasitology. 117: 229-234.

71 Dubey J.P., Shen S.K., Kwok O.C. \& Frenkel J.K. 1999. Infection and immunity with the RH strain of Toxoplasma gondii in rats and mice. Journal of Parasitology. 85: 657-662.

72 Duran F.P., Cabral D.D., Ferreira F.A., Silva D.A.O., Mineo J.R. \& Souza M.A. 1997. Frequência de anticorpos antiToxoplasma gondii (Nicolle \& Manceaux, 1909), em cães clinicamente sadios da cidade de Uberlândia-MG. In: I Congresso de Zoonoses (Rio de Janeiro, Brasil). p.228.

73 El-Malky M., Shaohong L., Kumagai T., Yabu Y., Noureldin M.S., Saudy N., Maruyama H. \& Ohta N. 2005. Protective effect of vaccination with Toxoplasma lysate antigen an $\mathrm{CpG}$ as an adjuvant against Toxoplasma gondii in susceptible C57BL/6 Mice. Microbiology Immunology. 49: 639-646.

74 Escopelli K.S. 2004. Avaliação sorológica de anticorpos para Toxoplasma gondii em soros de ovinos da região da Grande Porto Alegre/RS, através das técnicas de Hemaglutinação Indireta (HAI) e Imunofluorescência Indireta (IFI). 86f. Porto Alegre - RS. Dissertação (Mestrado em Ciências Veterinárias). Programa de Pós-Graduação em Ciências Veterinárias. Universidade Federal do Rio Grande do Sul.

75 Faria E.B., Gennari S.M., Pena H.F.J., Athayde A.C.R., Silva M.L.C.R. \& Azevedo S.S. 2007. Prevalence of antiToxoplasma gondii and anti-Neospora caninum antibodies in goats slaughtered in the public slauthterhouseof Patos city, Paraíba State, Northeast region of Brazil. Veterinary Parasitology. 149: 126-129.

76 Farrel R.L., Docton F.L., Chamberlain D.M. \& Cole C.R. 1952. Toxoplasmosis. Toxoplasma isolated from swine. American Journal of Veterinary Research. 13: 181-184.

77 Feldman H. \& Miller L. 1956. Serological study of toxoplasmosis prevalence. American Journal of Hygiene. 64: 320-335.

78 Fernandes W.J. \& Barbosa W. 1972. Toxoplasmose - Notas sobre sua ocorrência em animais domésticos em Goiânia (1970). Revista de Patologia Tropical. 1: 259-265.

79 Fialho C.G. \& Araujo F.A.P. 2003. Detecção de anticorpos para Toxoplasma gondii em soros de suínos criados e abatidos em frigoríficos da região da Grande Porto Alegre-RS, Brasil. Ciência Rural. 33: 893-897. 
80 Figliuolo L.P.C., Kasai N., Ragoso A.M.A., De Paula V.S.O., Dias R.A., Souza S.L.P. \& Gennari S.M. 2004. Prevalence of anti-Toxoplasma gondii and anti-Neospora caninum antibodies in ovine from São Paulo State, Brazil. Veterinary Parasitology. 23: 161-166.

81 Figliuolo L.P.C., Rodrigues A., Viana R., Aguiar D., Kasai N. \& Gennari S.M. 2004. Prevalence of Toxoplasma gondii and anti-Neospora caninum antibodies in goats from São Paulo State, Brazil. Small Ruminant Research. 55: 29-32.

82 Figueiredo J.F., Cabral D.D. \& Silva D.A.O. 1997. Frequência de anticorpos anti-Toxoplasma gondii em caprinos da região de Uberlândia, Minas Gerias. In: XXV Congresso Brasileiro de Medicina Veterinária (Gramado, Brasil). p.193.

83 Foulon W., Naessens A. \& Ho-Yen D. 2000. Prevention of congenital toxoplasmosis. Journal of perinatal medicine. $28: 337-343$.

84 Frazão-Teixeira E., Oliveira F.G.R., Pelissari-Sant'Ana V. \& Lopes C.W.G. 2006. Toxoplasma gondii em encéfalos de suínos comercializados no município de Campos do Goytacazes, Estado do Rio de Janeiro, Brasil. Revista Brasileira de Parasitologia Veterinária. 15: 33-36.

85 Freire R.L., Giraldi N., Vidotto O. \& Navarro I.T. 1995. Levantamento soroepidemiológico da toxoplasmose em ovinos na regiäo de Londrina, Paraná / Epidemiological study of ovine toxoplasmosis in Londrina region, Parana State, Brazil. Arquivo Brasileiro de Medicina Veterinária e Zootecnia. 47: 609-612.

86 Freire R.L., Navarro I.T., Bracarense A.P.F.R.L. \& Gennari S.M. 2003. Vaccination of pigs with Toxoplasma gondii antigens incorporated in immunostimulating complexes (iscoms). Arquivo Brasileiro de Medicina veterinária e Zootecnia. 55: 388-396.

87 Frenkel J.K. 1997. Toxoplasmose. In: Veronesi R. \& Foccacia R. (Eds). Tratado de Infectologia. São Paulo: Atheneu, 1803 p.

88 Frenkel J.K., Dubey J.P. \& Miller N.L. 1970. Toxoplasma gondii in cats: fecal stage identified as coccidian oocysts. Science. 167: 893-986.

89 Freyre A., Choromanski L., Fishback J.L. \& Popiel I. 1993. Immunization of cats with tissue cysts, brayzoites, and taquizoites of the T-263 stran of Toxoplasma gondii. Journal of Parasitology. 79: 716-719.

90 Freyre A., Fálcon J., Méndez J., González M., Venzal J.M. \& Morgades D. 2003. Fetal Toxoplasma infection after oocyst inoculation of pregnant rats. Parasitology Research. 89: 352-353.

91 Freyre A., Fálcon J., Méndez J., Rodriguez A., Correa L. \& González M. 2006. Refinement of the Mouse model of congenital toxoplasmosis. Experimental Parasitology. 113: 154-160.

92 Fujii T.U., Kasai N., Vasconcellos S.A., Richtzenhain L.J., Cortez A., Souza S.L.P., Baruselli P.S., Nishi S.M., Ferreira F. \& Gennari S.M. 2001. Anticorpos anti-Neospora caninum e contra outros agentes de abortamentos em búfalas da Região do Vale do Ribeira São Paulo, Brasil. Arquivos do Instituto Biológico. 68: 5-9.

93 Garcia J.L., Navarro S.M., Navarro I.T., Machado R.Z., Sinhorini I.L., Freire R.L., Marana R.M., Tsutsui V., Contente A.P.A. \& Begale L.P. 2005. Partial protection against tissue cysts formation in pigs vaccinated with crude rhoptry proteins of Toxoplasma gondii. Veterinary Parasitology. 129: 209-217.

94 Garcia J.L., Navarro I.T., Ogawa L. \& Marana E.R.M. 2000. Soroprevalência do Toxoplasma gondii em galinhas (Gallus gallus domesticus) de criações domésticas, oriundas de propriedades rurais do norte do Paraná, Brasil. Ciência Rural. 30: 123-127.

95 Garcia J.L., Navarro I.T., Ogawa L., Oliveira R.C. \& Kobilka E. 1999. Soroprevalência, epidemiologia e avaliação ocular da toxoplasmose humana na zona rural da Jaguapitã (Paraná), Brasil. Revista Panamericana de Salud Pública. 6: 157-163.

96 Garcia J.L., Navarro I.T., Ogawa L. \& Oliveira R.C. 1999. Soroepidemiologia da toxoplasmose em gatos e cães de propriedades rurais do município de Jaguapitã, estado do Paraná, Brasil. Ciência Rural. 29: 99-104.

97 Garcia J.L., Navarro I.T., Ogawa L. \& Oliveira R.C. 1999. Soroprevalência do Toxoplasma gondii, em suínos, bovinos, ovinos e equinos, e sua correlação com humanos, felinos e caninos, oriundos de propriedades rurais do norte do Paraná, Brasil. Ciência Rural. 29: 91-97.

98 Gazêta G.S., Dutra A.E.A., Norberg A.N., Serra-Freire N.M., Souza W.J.S.,Amorin M. \& Lopes L.M.S. 1997. Freqüência de anticorpos anti-Toxoplasma gondii em soros de equinos no estado do Rio de Janeiro, Brasil. Revista Brasileira de Parasitologia Veterinária. 6: 87-91.

99 Germano P.M.L., Erbolato E.B. \& Ishizuka M.M. 1985. Estudo sorológico da toxoplasmose canina, pela prova de imunofluorescência indireta, na cidade de Campinas, 1981. Revista da Faculdade de Medicina Veterinária e Zootecnia da USP. 22: 53-58.

100 Giovannoni M. 1958. Considerações sobre o Toxoplasma e a toxoplasmose. Isolamento do agente etiológico e pesquisa de anticorpos em cães. Curitiba - PR. 64f. Tese (Doutorado em Ciências Veterinárias). Programa de Pós-Graduação em Ciências Veterinárias. Universidade Federal do Paraná. 
101 Gonçalez C.C. 2008. Pesquisa de anticorpos anti-Leptospira spp., Toxoplama gondii e Neospora caninum em cães recolhidos das ruas e albergados em canil privado de Avaré-SP. 134f. Botucatu - SP. Dissertação (Mestrado em Medicina Veterinária). Programa de Pós-Graduação em Medicina Veterinária, Universidade Estadual Paulista (UNESP).

102 Gondim L.F.P., Barbosa H.V., Ribeiro Filho C.H.A. \& Saeki H. 1999. Serological survey of antibodies to Toxoplasma gondii in goats, sheep, cattle and water buffaloes in Bahia State, Brasil. Veterinary Parasitology. 82: 273-276.

103 Grünspan E.D. 1996. Isolamento de Toxoplasma gondii em praça pública da cidade de Santa Maria, RS, Brasil. Santa Maria - RS. 68p. Dissertação (Mestrado em Medicina Veterinária Preventiva) - Programa de Pós-Graduação em Medicina Veterinária. Universidade Federal de Santa Maria.

104 Grünspan E.D., Moreira W.S., Edelweiss M.I.A., Ulon S.N. \& Daudt H.M.L. 1995. Imunoglobulinas antitoxoplásmicas e retinocoroidite em suínos. Ciência Rural. 25: 261-264.

105 Guimarães A.M., Ribeiro M.F.B., Lima J.D. \& Almeida T.M.B. 1992. Frequência de anticorpos anti-Toxoplasma gondii em suínos da raça Piau. Arquivo Brasileiro Medicina Veterinária e Zootecnia. 44: 69-71.

106 Guimarães A.M., Ribeiro M.F.B., Lima J.D., Cury M.C. \& Spiewak G. 1992. Frequência de anticorpos anti-Toxoplasma gondii em cães de Belo Horizonte, Minas Gerais. Arquivo Brasileiro de Medicina Veterinária. 44: 67-68.

107 Higa A.C., Machado R.Z., Tinucci-Costa M., Domingues L.M. \& Malhueiros, E.B. 2000. Evaluation of cross-reactivity of Toxoplasma gondii and Neospora caninum antigens in dogs sera. Revista Brasileira de Parasitologia Veterinária. 9: 91-95.

108 Hutchison W.M. 1967. The nematode transmission of Toxoplasma gondii. The Royal Society of Tropical Medicine and Hygiene. 61: 80-89.

109 Ishizuka M.M. 1978. Avaliação da frequência de reagentes ao Toxoplasma gondii, pela prova de imunofluorescência indireta em suínos de matadouro do município de São Paulo. Revista da Faculdade de Medicina Veterinária e Zootecnia da USP. 15: 151- 154.

110 Ishizuka M.M. \& Yasuda P.H. 1981. Incidência de infecção por Toxoplasma gondii em cães do município de São Paulo. Revista da Faculdade de Medicina Veterinária e Zootecnia da USP. 18: 161-165.

111 Ishizuka M.M., Miguel O. \& Brogliato D.F. 1974. Estudo comparativo entre as provas de Sabin-Feldman e imunofluorescência indireta para a avaliação de anticorpos anti-Toxoplasma em soros de cães. Revista da Faculdade de Medicina Veterinária e Zootecnia da USP. 11: 127-132.

112 Ito S., Tsunoda K., Tsutsumi Y., Matsui T., Nishikawa H., Iida T. \& Sasaki Y. 1975. Detection and confirmation of Toxoplasma oocysts in the soil. Japanese Journal of Veterinary Science. 37: 549-554.

113 Kawazoe U. 2005. Toxoplasma gondii. In: Neves D.P. (Ed.) Parasitologia Humana. 11.ed. São Paulo: Atheneu, 494p.

114 Lagaggio V.R.A., Flores M.L., Alves C.S.P., Silva D.C., Barcelos A.B., Katzer L.H., Barcelos A.S., Lazzarotto J.J., Cenci A. \& Noal S.A. 1997. Hemaglutinação passiva para toxoplasmose em cães da região Central do RS. Revista Brasileira de Parasitologia Veterinária. 6: 342.

115 Langoni H., Modolo J.R., Pezerico S.B., Silva R.C., Castro A.P.B., Silva A.V. \& Padovani C.R. 2006. Serological profile of anti-Toxoplasma gondii antibodies in apparently healthy dogs of the city of Botucatu, São Paulo State, Brazil. Journal of Venomous Animals and Toxins including Tropical Diseases. 12: 142-148.

116 Langoni H., Silva A.V., Cabral K.G., Cunha E.L.P. \& Cutolo A.A. 2001. Nota prévia. Prevalência de toxoplasmose em gatos dos Estados de São Paulo e Paraná. Brazillian Journal of Veterinary Research and Animal Science. 38: $243-244$.

117 Lappin M.R. 1994. Toxoplasmosis felina. Waltham focus. 4: 2-8.

118 Laranjeira N.L., Ishizuka M.M. \& Hyakutaki S. 1985. Prevalência da toxoplasmose equina avaliada pela técnica de imunofluorescência indireta no Mato Grosso do Sul, Brasil. Boletin de la Oficina Sanitaria Panamericana. 64: 58-61.

119 Larsson L.E. 1980. Prevalência de toxoplasmose ovina determinada pela Reação de Sabin-Feldman em animais de Uruguaiana, RS, Brasil. Revista de Saúde Pública. 14: 582-588.

120 Lazzarotto J.J., Lagaggio V.R.A., Barcelos A.S., Silva D.C. \& Katzer L.H. 1997. Estudo da prevalência da infecção por Toxoplasma gondii em bovinos de leite do município de Santa Maria com caracterização parcial das propriedades investigadas. In: IV Jornada Integrada de Pesquisa, Extensão e Ensino, Universidade Federal de Santa Maria-RS (Santa Maria, Brasil). p.727.

121 Levine N.D., Corliss J.O., Cox F.E.G., Deroux G., Grain J., Honigberg B.M., Leedale G.F., Loeblich A.R., Lom J., Lynn D., Merinpeld E.G., Page F.C., Poljansky G., Sprague V., Vavra J. \& Wallace F.G. 1980. A newly revised classification of the Protozoa. Journal Protozoology. 27: 37-58. 
122 Levine N.D. 1985. Veterinary Protozoology. Ames: Iowa State University Press, 414p.

123 Lima J.N., Felício P.S., Franco P.M., Lara M.C.C.S., Cunha E.M.S., Quaglieri D., Gomes L.O., Villalobos E.M.C. 2007. Ocorrência de anticorpos anti-Toxoplasma gondii (Nicolle \& Manceaux, 1908) em suínos abatidos em matadouros no estado de São Paulo, SP, Brasil. O Biológico. 67: 25-51

124 Lima J.T., Ahid S.M.M., Barreto Júnior R.A., Pena H.F.J., Dias R.A. \& Gennari S.M. 2008. Prevalência de anticorpos anti-Toxoplasma gondii e anti-Neospora caninum em rebanhos caprinos do município de Mossoró, Rio Grande do Norte. Brazilian Journal Research Animal Science. 45: 81-86.

125 Lindsay D.S., Dubey J.P., Butler J.M. \& Blagburn B.L. 1997. Mechanical transmission of Toxoplasma gondii oocysts by dogs. Veterinary Parasitology. 73: 27-33.

126 Lucas S.R.R., Hagiwara M.K., Loureiro V.S., Ikesaki J.Y. \& Birgel E.H. 1999. Toxoplasma gondii infection in Brazillian domestic outpatient cats. Revista do Instituto de Medicina Tropical de São Paulo. 41: 221-224.

127 Lucas S.R.R., Hagiwara M.K., Reche A. \& Germano P.M. 1998. Ocorrência de anticopos antitoxoplasma em gatos infectados naturalmente pelo vírus da imunodeficiência dos felinos. Brazilian Journal of Veterinary Research and Animal Science. 35: 41-45.

128 Machado T.M.M. \& Lima J.D. 1987. Frequência de anticorpos anti-Toxoplasma gondii em caprinos criados sob diferentes formas de exploração no estado de Minas Gerais. Arquivo Brasileiro de Medicina Veterinária e Zootecnia. 39: $255-264$.

129 Maciel K.P. \& Araujo F.A.P. 2004. Inquérito sorológico para a detecção de anticorpos de Toxoplasma gondii em caprinos (Capra hircus) criados nos municípios de Gravataí e Viamão, região da Grande Porto Alegre, Rio Grande do Sul, Brasil. Revista de Ciências Agroveterinárias. 3: 121-125.

130 Macruz R., Oswaldo L., Ishizuka M.M., Omar M. \& Cunha R.A.F. 1974. Toxoplasmose em equinos PSI. In: XIV Congresso Brasileiro de Medicina Veterinária (São Paulo, Brasil). p 128.

131 Mainardi R.S., Stachissini A.V.M., Langoni H., Padovani C.R. \& Modolo J.R. 2000. Soroprevalência de Toxoplasma gondii em rebanhos caprinos no estado de São Paulo. Revista Brasileira de Parasitologia Veterinária. 9: 97-99.

132 Marana E.R.M., Navarro I.T., Vidotto O., Freire R.L. \& Lott R. 1994. Ocorrência de anticorpos anti-Toxoplasma gondii em bovinos de corte, abatidos em matadouros do Norte do Paraná - Brasil. Semina: Ciências Agrárias. 15: 38-40.

133 Marques L.C. \& Costa A.J. 1982. Infecção experimental de ovinos com oocistos e cistos de Toxoplasma gondii Nicolle \& Manceaux, 1909. In: XVIII Congresso Brasileiro de Medicina Veterinária (Balneário Camboriú, Brasil). p. 202.

134 Marques L.C., Costa A.J., Lopes C.W.G. \& Neto J.C.L. 1998. Experimental toxoplasmosis in pregnant mares: clinical signs, parasitemia and immunological observations. Semina: Ciências Agrárias. 19: 45-49.

135 Martins J.R. \& Hancock R. 1991. Ocorrência de anticorpos contra Toxoplasma gondii em ovinos do RS: prevalência e implicações epidemiológicas. In: VII Seminário Brasileiro de Parasitologia Veterinária. Revista Brasileira de Parasitologia Veterinária (São Paulo, Brasil). 1: 1-6

136 Martins J.R., Hancock R., Corrêa, B.L. \& Caresér V.H. 1998. Ocorrência de anticorpos contra Toxoplasma gondii em ovinos no município de Livramento, RS: prevalência e implicações epidemiológicas. Pesquisa Agropecuária Gaúcha. 4: 27-29.

137 Matos M.P.C., Sobestiansky J., Gambarini M.L. \& Caiado K.L. 1999. Anticorpos para Toxoplasma gondii em soros de matrizes suínas de granjas que abastecem o mercado consumidor de Goiânia. A Hora Veterinária. 109: 9-11.

138 Meireles L.R. 2001. Estudo das fontes de infecção da toxoplasmose humana em diferentes localidades do Estado de São Paulo. São Paulo - SP. 141f. Dissertação (Mestrado em Ciências Biológicas). Programa de Pós-Graduação em Biologia da relação Patógeno-Hospedeiro, Universidade de São Paulo.

139 Meireles M.V., Paulillo A.C., Costa A.J., Moraes F.R., Ávila F.A. \& Silva G.S. 1995. Correlação entre Toxoplasma gondii e Cryptosporidium baileyi em frangos de corte experimentalmente infectados. Revista Brasileira de Parasitologia Veterinária. 4: 105-112.

140 Mello V. 1910. Un cas de toxoplasmose du chien observé à Turín. Bulletin Society Pathology. 28: 359-363.

141 Mendez L.D.V. 1983. Prevalência de coccídios e anticorpos anti-toxoplásmicos em gatos domésticos de Porto Alegre-RS, Brasil. Porto Alegre-RS. 38p. RS. Dissertação (Mestrado em Ciências Veterinárias) Programa de Pós-Graduação em Ciências Veterinárias, Universidade Federal do Rio Grande do Sul.

142 Mendonça A.O., Cerqueira E.J.L., Araújo W.N., Moraes-Silva E., Shimabukuru F.H., Sarkis D.T., Sherlock I. \& Langoni H. 2001. Inquérito sorológico para toxoplasmose em equídeos procedentes de duas regiões do Estado da Bahia, Brasil. Semina: Ciências Agrárias. 22: 115-118. 
143 Millar P.R., Daguer H., Vicente R.T., Costa T., Sobreiro L.G. \& Amendoeira M.R.R. 2008. Toxoplasma gondii: estudo soroepidemiológico de suínos da região Sudoeste do Estado do Paraná. Pesquisa Veterinária Brasileira. 28: 15-18.

144 Mineo T.W.P., Silva D.A.O., Costa G.H.N., Ancken A.C.B., Kasper L.H., Souza M.A., Cabral D.D., Costa A.J. \& Mineo J.R. 2001. Detection of IgG antibodies to Neospora caninum and Toxoplasma gondii in dogs examined in a veterinary hospital from Brazil. Veterinary Parasitology. 98: 239-245.

145 Mineo T.W.P., Silva D.A.O., Näslund K., Jjörkman C., Uggla A. \& Mineo J.R. 2004. Toxoplasma gondii and Neospora caninum serological status of different canine populations from Uberlândia, Minas Gerais. Arquivo Brasileiro de Medicina Veterinária e Zootecnia. 56: 414-417.

146 Montoya J.G. \& Liesenfeld D.O. 2004. Toxoplasmosis. Lancet. 363: 1965-1976.

147 Moreno A.M., Linhares G.F.C., Sobestiansky J., Matos M.P.C. \& Barcellos D. 2007. Doenças em Suínos. In: Sobestiansky J. \& Barcellos D. (Eds). Goiânia: Cânone, 770p.

148 Moura A.B., Osaki S.C., Zulpo D.L. \& Marana E.R.M. 2007. Ocorrência de anticorpos contra Toxoplasma gondii em suínos e ovinos abatidos no município de Guarapuava, PR, Brasil. Revista Brasileira de Parasitologia Veterinária. 16: 54-56.

149 Navarro I.T., Freire R.L. \& Passos J. 1994. Toxoplasma gondii: animais envolvidos em surto de toxoplasmose humana. Revista da Sociedade Brasileira de Medicina Tropical. 27: 516.

150 Navarro I.T., Freire R.L., Vidotto O., Ogawa L. \& Kano F.S. 1997. Estudo comparativo entre soros e plasma na pesquisa de anticorpos anti-Toxoplasma gondii pela técnica de imunofluorescência em cães atendidos no hospital veterinário da Universidade Estadual de Londrina - PR. Semina: Ciências Agrárias. 18: 15-21.

151 Navarro I.T., Lisboa J.A.N., Reichmann P., Freire R.L., Contente A.P.A., Marana E.R.M., Prado J.P., Prudencio L.B. \& Tsutsui V.S. 2002. Estudo soroepidemiológico de anticorpos anti-Toxoplasma gondii em equinos atendidos no hospital veterinário da Universidade Estadual de Londrina-PR. In: XII Congresso Brasileiro de Parasitologia Veterinária (Rio de Janeiro, Brasil). p.89.

152 Navarro I.T., Vidotto O., Giraldi N. \& Mitsuka R. 1992. Resistência do Toxoplasma gondii ao cloreto de sódio e aos condimentos em linguiça de suínos. Boletin de la Oficina Sanitaria Panamericana. 112: 138-143.

153 Navarro I.T., Vidotto O., Silva A.C.B., Mitsukica R., Jankevinicius J.V., Shida P.N. \& Cortês J.A. 1998. Comportamento Imunológico e antigênico de cinco amostras de Toxoplasma gondii inoculadas em gatos. Ciência Rural. 28: 453-459.

154 Naves C.S., Ferreira F.A., Carvalho F.S.R. \& Costa G.H.N. 2005. Soroprevalência da toxoplasmose em equinos da raça Mangalarga Marchador no Município de Uberlândia, Minas Gerais. Veterinária Notícias. 11: 45-52.

155 Neto V.A. \& Marchi C.R. 1999. Toxoplasmose. In: Cimerman B. \& Cimerman S. (Eds). Parasitologia Humana e seus Fundamentos Gerais. São Paulo: Atheneu, 375p.

156 Netto E.G., MunhozA.D.,Albuquequerque G.R., Lopes C.W.G. \& FerreiraA.M.R. 2003. Ocorrência de gatos soropositivos para Toxoplasma gondii Nicolle \& Manceaux, 1909 (Apicomplexa: Toxoplasmatinae) na cidade de Niterói, Rio de Janeiro. Revista Brasileira de Parasitologia Veterinária. 12: 145-149.

157 Neves D.P. 2003. Parasitologia dinâmica. São Paulo: Atheneu, 474p.

158 Nicolle C. \& Manceaux L. 1908. Sur une infectio a corps de Leishmania (ou du organismes voisins) du gondi. Comptes Rendus Academy Science. 147: 763-766.

159 Nicolle C. \& Manceaux L. 1909. Sur une protozoaire nouveau du gondii, Toxoplasma. Archives de L'institut Pasteur de Tunis. 2: 216-218.

160 Nóbrega P., Trapp E. \& Giovannoni M. 1955. Toxoplasmose espontânea da galinha. Arquivo do Instituto de Biologia. 22: $43-49$.

161 Ogawa L., Freire R.L., Vidotto O., Gondim L.F.P. \& Navarro I.T. 2005. Ocorrência de anticorpos contra Neospora caninum e Toxoplasma gondii em bovinos leiteiros da região norte do Estado do Paraná. Arquivo Brasileiro de Medicina Veterinária e Zootecnia. 57: 312-316.

162 Ogawa L., Navarro I.T., Freire R.L., Oliveira R.C. \& Vidotto O. 2003. Occurrence of antibodies to Toxoplasma gondii in sheep. Semina: Ciências Agrárias. 24: 57-62.

163 Oliveira F.C.R., Costa A.J. \& Sabatini G.A. 2000. Anticorpos em bovinos (Bos indicus e Bos taurus) e bubalinos (Bubalus bubalis) inoculados com oocistos de Toxoplasma gondii. Estudo comparativo. Arquivo Brasileiro de Medicina Veterinária e Zootecnia. 52: 331-336. 
164 Oliveira L.L.S., Spagnol F.H., Medeiros S.M., Lopes C.W.G. \& Albuquerque G.R. 2005. Frequência de anticorpos antiToxoplasma gondii em bovinos no matadouro municipal de Itabuna, Bahia. In: $11^{\circ}$ Seminário de Iniciação Científica da UESC (Florianópolis, Brasil). pp.125-126.

165 Oliveira-Sequeira T.C.L., Amarante A.F.T., Salata E. \& Sogayar R. 1993. Serological survey for Toxoplasma gondii infection in sheep in São Paulo State, Brazil. Veterinária e Zootecnia. 5: 121-125.

166 Passos J.N., Bonametti A.M. \& Passos E.M. 1994. Relato de um caso de toxoplasmose aguda com provável transmissão através do aleitamento materno. Revista da Sociedade Brasileira de Medicina Tropical. 27: 516.

167 Passos L.M.F. \& Figueiredo B.L. 1984. Determinação da infecção por Toxoplasma gondii em bovinos e suínos abatidos em Belo Horizonte, Minas Gerais para se conhecer a frequência de anticorpos e tentativa de isolamento a partir de músculos de bovino. In: XIX Congresso Brasileiro de Medicina Veterinária (Belém, Brasil). p.378.

168 Passos L.M.F., Lima J.D. \& Fiqueiredo B.L. 1984. Determinação da infecção por Toxoplasma gondii em bovinos abatidos em Belo Horizonte (MG) através da frequência de anticorpos e tentativa de isolamento a partir de musculatura diafragmática. Arquivo Brasileiro de Medicina Veterinária e Zootecnia. 36: 581-589.

169 Pena H.F.J., Soares R.M., Dubey J.P. \& Gennari S.M. 2006. Toxoplasma gondii infection in cats from São Paulo State, Brazil: seroprevalence, oocyst shedding, isolation in mice, and biologic and molecular characterization. Reserch in Veterinary Science. 18: 58-67.

170Pereira I.C. 2005. Soroprevalência de anticorpo para Toxoplasma gondii em suínos e características epidemiológicas de estabelecimentos de criação industrial e artesanal da região de Pelotas-RS. Pelotas - RS. 99p. Dissertação (Mestrado em Veterinária). Programa de Pós-Graduação em Veterinária, Universidade Federal de Pelotas.

171 Pescador C.A., Oliveira E.C., Pedroso P.M.O., Bandarra P.M., Okuda L.H., Corbellini L.G. \& Driemeier D. 2007. Perdas reprodutivas associadas com infecção por Toxoplasma gondii em caprinos no sul do Brasil. Pesquisa Veterinária Brasileira. 27: 167-171.

172 Pezerico G.P., Pezerico S.B., Silva R.C., Hoffmann J.L., Camargo L.B. \& Langoni H. 2007. Ocorrência de anticorpos anti-Toxoplasma gondii e anti-Leptospira spp. em suínos abatidos em três abatedouros dos estados de Minas Gerais e São Paulo. Arquivos do Instituto Biológico. 74: 267-270.

173 Pinto L.D. 2007. Soroepidemiologia do Toxoplasma gondii em felinos domiciliados atendidos em clínicas particulares de Porto Alegre, RS, Brasil. 76p. Porto Alegre, RS. Dissertação (Mestrado em Ciências Veterinárias). Programa de PósGraduação em Ciências Veterinárias, Universidade Federal do Rio Grande do Sul.

174 Pizzi H.L. 1997. Toxoplasmosis. Argentina: Rhône Poulenc Rorer Argentina, 91p.

175 Porto W.J.N., Ribeiro T.C.E.S., LeiteA.S., Alves L.C., Barbosa C.L., Mota R.A., Pereira G.C. \& Carvalho Júnior G.M. 1999. Frequência de suínos sororeagentes para Toxoplasma gondii na região metropolitana do Recife. In: XII Congresso Brasileiro de Parasitologia Veterinária (Salvador, Brasil). p.219.

176 Powell C.C., Brewer M. \& Lappin M.R. 2001. Detection of Toxoplasma gondii in the milk of experimentally infected lactating cats. Veterinary Parasitology. 102: 29-33.

177 Ragoso A.M.A., Azevedo S.S., Vasconcellos S.A., Batista C.S.A., Aguiar D.M., Rodrigues A.A.R., Alves C.J. \& Gennari S.M. 2004. Toxoplasma gondii em cães na cidade de Campina Grande, Paraíba: soroepidemiologia e fatores de risco. In: XIII Congresso Brasileiro de Parasitologia Veterinária (Ouro Preto, Brasil). p.217.

178 Reis C.R., Reis H.R., Gonçalves D.D., Lopes F.M.R., Carletti R.T., Silva M.F., Freire R.L. \& Navarro I.T. 2004. Levantamento sorológico da toxoplasmose em case de Bela Vista do Paraíso, Paraná, Brasil. In: XIII Congresso Brasileiro de Parasitologia Veterinária (Ouro Preto, Brasil). p.211.

179 Remington J.S. \& Desmonts G. 1995. Toxoplasmosis. In: Remington J.S \& Klein J.O. (Eds). Infectious diseases of the Fetus and Newborn Infant. 4th edn. Philadelphia: Saunders, 1373 p.

180 Romanelli P.P., Freire R.L., Vidotto O., Marana E.R.M., Ogawa L., De Paula V.S.O., Garcia J.L. \& Navarro I.T. 2007. Prevalence of Neospora caninum and Toxoplasma gondii in sheep and dogs from Guarapuava farms, Paraná State, Brazil. Research in Veterinary Science. 82: 202-207.

181 Rosa J.A., Buainain A. \& Belda Neto F.M. 1986/1987. Toxoplasma gondii em gatos da cidade de Araraquara-SP - Estudo sorológico e coproparasitológico. Revista Brasileira de Ciências Farmacêuticas. 8/9: 105-111.

182 Rosa C., Langoni H., Silva A.V., Marinho M. \& Listoni F.J.P. 1997. Levantamento de anticorpos anti-Toxoplasma gondii em soros de ovinos no Estado de São Paulo. Revista Brasileira de Parasitologia Veterinária. 6: 334-337. 
183 Rosado I.R., Guimarães A.M. \& Oliveiro T.M.F.S. 2004. Prevalência de anticorpos anti-Toxoplasma gondii em cães atendidos em clínicas veterinárias de Lavras, Minas Gerias. In: XIII Congresso Brasileiro de Parasitologia Veterinária (Ouro Preto, Brasil). p.217.

184 Santana L.F. 2007. Toxoplasmose experimental em caprinos machos com ênfase no sistema reprodutor. 96f. Jaboticabal - SP. Dissertação (Mestrado em Medicina Veterinária). Programa de Pós-Graduação em Medicina Veterinária. Universidade Estadual de São Paulo.

185 Santos S.M., Amaral V., Rebouças M.M. \& Drumond L.S. 1983. Anticorpos antitoxoplasma detectados por hemaglutinação indireta em soros de gatos domésticos provenientes da capital de São Paulo, Brasil. O Biológico. 49: 163-165.

186 Santos S.M., Amaral V. \& Rebouças M.M. 1978. Prevalência de anticorpos antitoxoplasma, por hemaglutinação indireta, em soros de suínos provenientes de diferentes municípios do estado de São Paulo. O Biológico. 44: 149-153.

187 Schenk M.A.M., Lima J.D. \& Viana F.C. 1976. Freqüência e isolamento de Toxoplasma gondii em suínos do Estado de Minas Gerais. Arquivos da Escola de Veterinária da UFMG. 28: 261-266.

188 Sella M.Z., Navarro I.T., Vidotto O., Freire R.L. \& Shida P.N. 1994. Epidemiologia da toxoplasmose caprina: levantamento sorológico do Toxoplasma gondii em caprinos leiteiros na micro região de Londrina, Paraná, Brasil. Revista Brasileira de Parasitologia Veterinária. 3: 13-16.

189 Serra-Freire N.M., NorbergA.N. \& Gazeta G.S. 1994. Toxoplasmose caprina no Rio de Janeiro. Parasitologia al Dia. 18 : $77-81$.

190 Silva A. V., Cunha E.L.P. \& Meireles L.R. 2003. Toxoplasmose em ovinos e caprinos: estudo soroepidemiológico em duas regiões do Estado de Pernambuco, Brasil. Ciência Rural. 33: 115-119.

191 Silva A.V., Cutolo A.A. \& Langoni H. 2002. Comparação da reação de imunofluorescência indireta e do método aglutinação direta na detecção de anticorpos anti-Toxoplasma em soros de ovinos, caprinos, caninos e felinos. Arquivos do Instituto Biológico. 69: 7-11.

192 Silva A.V. \& Langoni H. 2000. Alimentos de origem animal e a toxoplasmose humana. Higiene Alimentar. 14: 34-39.

193 Silva A.V. \& Langoni H. 2001. The detection of Toxoplasma gondii by comparing cytology, histopathology, bioassayin mice and the polymerase chain reaction (PCR). Veterinary Parasitology. 97: 191-198.

194 Silva D.A.O., Cabral D.D., Bernardina B.L.D., Souza M.A. \& Mineo J.R. 1997. Detection of Toxoplasma gondiispecific antibodies in dogs. A comparative study of immunoenzymatic, immunofluorescent and haemagglutination titers. Memórias do Instituto Oswaldo Cruz. 92: 785-789.

195 Silva D.A.O., Silva N.M., Mineo T.W.P., Pajuaba Neto A., Ferro E.A.V. \& Mineo J.R. 2002. Heterologous antibodies to evaluate the kinetics of the humoral immune response in dogs experimentally infected with Toxoplasma gondii RH strain. Veterinary Parasitology. 107: 181-195.

196 Silva J.C.R., Gennari S.M., Ragozo A.M.A., Amajones V.R., Magnabosco C., Yai L.E.O., Ferreira-Neto J.S. \& Dubey J.P. 2002. Prevalence of Toxoplasma gondii antibodies in sera of domestics cats from Guarulhos and São Paulo, Brasil. Journal of Parasitology. 88: 419-420.

197 Silva J.M.L. 1959. Sobre um caso de Toxoplasmose espontânea em suínos. Arquivos da Escola Superior de Veterinária. 12: 425-428.

198SILVA K.L.M.V. 2001. Análise de transmissão congênita de Toxoplasma gondii (Nicolle \& Manceaux, 1909) em ovinos em duas propriedades no município de Rosário de Sul. Santa Maria - RS. 16f. Dissertação (Mestrado em Medicina Veterinária). Programa de Pós-Graduação em Medicina Veterinária. Universidade Federal de Santa Maria.

199Silva K.L.M.V. \& Rue M.L. 2006. Possibilidade de transmissão congênita de Toxoplasma gondii em ovinos através de seguimento sorológico no município de Rosário do Sul, RS, Brasil. Ciência Rural. 36: 892-897.

200 Silva N.R.S., Chaplin E.L., Araujo, F.A.P. \& Mendez L.D.V. 1982/83. Frequência de anticorpos de Toxoplasma gondii em soros de bovinos de leite da Grande Porto Alegre, RS. Arquivos da Faculdade de Veterinária da UFRGS. 10-11: 81-84.

201 Silva N.R.S., Chaplin E.L., Araujo F.A.P. \& Pereira R.A.P. 1981. Prevalência de anticorpos toxoplásmicos em soros de equinos no município de Porto Alegre, RS. Arquivos da Faculdade de Veterinária da UFRGS. 9: 105-107.

202 Silva N.R.S., Chaplin E.L., Mendez L.D.V. \& Araújo F.A.P. 1981. Determinação de anticorpos toxoplásmicos em soros de suínos obtidos em matadouros, na região do Alto Taquari, RS, Brasil. Arquivos da Faculdade de Veterinária da UFRGS. 9: 33-38.

203 Silva N.R.S., Costa A.J., Chaplin E.L. \& Souza S.M.G. 1981. Prevalência de anticorpos toxoplásmicos em soros de ovinos, pela reação de imunofluorescência indireta (IFI), na região de Guaíba, RS. Arquivos da Faculdade de Veterinária da UFRGS. 9: 101-104. 
204 Silva N.R.S., Costa A.J. \& Souza S.M.G. 1980. Prevalência de anticorpos antitoxoplásmicos em ovinos, determinada pela reação de imunofluorescência indireta (RIFI), no município de São Lourenço do Sul, RS. Arquivos da Faculdade de Veterinária UFRGS. 8: 89-92.

205 Silveira C. 2001. Toxoplasmose - Levantamento bibliográfico de 1997-2000. Arquivos Brasileiros de Oftalmologia. 64: $263-270$.

206Sogorb F., Jamra L.F., Guimarães E.C. \& Deane M.P. 1972. Toxoplasmose espontânea em animais domésticos e silvestres em São Paulo. Revista do Instituto de Medicina Tropical de São Paulo. 14: 314-320.

207 Souza L.M., Nascimento A.A., Furuta P.I., Basso L.M.S., Silveira D.M. \& Costa A.J. 2001. Detecção de anticorpos contra Neospora caninum e Toxoplasma gondii em soros de bubalinos (Bubalus bubalis) no Estado de São Paulo, Brasil. Semina: Ciências Agrárias. 22: 39-48.

208 Souza S.L.P., Gennari S.M., Yai L.E.O., D’auria S.R.N., Cardoso S.M.S., Guimarães Junior J.S. \& Dubey J.P. 2003. Ocurrence of Toxoplasma gondii antibodies in sera from dogs of the urban and rural areas from Brazil. Revista Brasileira de Parasitologia Veterinária. 12: 1-3.

209Souza S.L.P., Ragozo A.M.A., Guimarães J.S., Ferreira F. \& Gennari S.M. 2001. Prevalência de anticorpos anti-T. gondii em cães de propriedades produtoras de leite B da região Norte do Estado do Paraná. Jornal Brasileiro de Patologia. 37: 46.

210Souza W.J.S. 1995. Epidemiologia da toxoplasmose: avaliação sorológica de suínos e trabalhadores em abatedouros na mesorregião do Grande Rio de Janeiro. 125f. Tese (Doutorado em Biologia Parasitária) - Programa de Pós-Graduação em Biologia Parasitária, Instituto Oswaldo Cruz.

211 Souza W.J.S., Andrade D.P.M., Furtado A.C., Neta M.B.F., Juvenal M.F., Berco S.P.S., Fernandes C.G.N. \& Moura S.T. 2001. Frequência de toxoplasmose canina em Mato Grosso - Cuiabá, Brasil. Jornal Brasileiro de Patologia. $37: 257$.

212 Splendore A. 1908. Um nuovo protozoo parassita de' conigli - incontrato nelle lesioni anatomiche d'une mallatia che ricorda in molti punti il kala-azar dell'uomo. Revista da Sociedade de Sciencias. 3: 109-112.

213Suárez F., Andrade H. \& Galisteo A. 1999. Evaluación serológica del Toxoplasma gondii en suinos mediante la prueba de ELISA. Revista de Investigaciones del Perú, [Fonte: http://sisbib.unmsm.edu.pe/bvrevistas/veterinaria/v10_n1/ vtoxoplasmag.htm]

214 Swango L.J., Bankemper K.W. \& Kong L.I. 1992. Infecções bacterianas, riquétsias, protozoais, e outras. In: Ettinger S.J. (Ed). Tratado de Medicina Interna Veterinária. 3.ed. São Paulo: Manole, 2557p.

215 Tsutsui V.S., Freire R.L., Garcia J.L., Gennari S.M., Vieira D.P., Marana E.R.M., Prudêncio L.B. \& Navarro I.T. 2007. Detection of Toxoplasma gondii by PCR and mouse bioassay in commercial cuts of pork from expermentally infected pigs. Arquivo Brasileiro de Medicina Veterinária e Zootecnia. 59: 30-34.

216 Tsutsui V.S., Prudencio L.B., Contente A.P.A., Freire R.L., Navarro I.T., Marana E.R.M., Delbem A.C.B. \& Stellatto R.A. 2001. Estudo soroepidemiológico e fatores associados à transmissão do Toxoplasma gondii em granjas de suínos do norte do Estado do Paraná. Jornal Brasileiro de Patologia.37: 255.

217 Ueno T.E.H. 2005. Prevalência das infecções por Toxoplasma gondii e Neospora caninum em matrizes e reprodutores ovinos de rebanhos comerciais do Distrito Federal, Brasil. 107f. São Paulo, SP. Dissertação (Mestrado em Epidemiologia experimental e aplicada as zoonoses) - Programa de Pós-Graduação Epidemiologia Experimental Aplicada as Zoonoses, Universidade de São Paulo.

218 Ulon S.N. 1996. Inquérito sorológico de infecção toxoplásmica em ovinos abatidos em Santa Maria, RS, e sua repercussão na saúde pública. Santa Maria -RS. 78f. Dissertação (Mestrado em Medicina Veterinária). Programa de Pós-Graduação em Medicina Veterinária. Universidade Federal de Santa Maria.

219Urquhart G.M., Armour J., Duncan J.L. \& Jennings F.W. 1998. Parasitologia Veterinária. 2.ed. Rio de Janeiro: Guanabara, 273p.

220 Uzêda R.S., Fernández S.Y., Jesus E.E.V., Pinheiro A.M., Ayres M.C.C., Spinola S., Barbosa Junior H.V. \& Almeida M.A.O. 2004. Fatores relacionados à presença de anticorpos IgG anti-Toxoplama gondii em caprinos leiteiros do Estado de Bahia. Revista Brasileira de Saúde e Produção Animal. 5: 1-8.

221 Varandas N.P., Rached P.A., Costa G.H.N., Souza L.M., Castagnolli K.C. \& Costa A.J. 2001. Freqüência de anticorpos anti-Neospora caninum e anti-Toxoplasma gondii em cães da região nordeste do estado de São Paulo. Correlação com neuropatias. Semina: Ciências Agrárias. 22: 105-111. 
222 Vargas C.S.G. 2006. Títulos de anticorpos da classe IgG anti-Toxoplasma gondii (Nicolle \& Manceaux, 1908) e de oocistos em fezes de gatos de rua (Felis catus- LINNAEUS, 1758) em Curitiba, Paraná. 66f. Dissertação (Mestrado em Medicina Veterinária). Programa de Pós-Graduação em Medicina Veterinária. Universidade Federal do Paraná.

223 Vasconcelos O.T., Costa A.J. \& Ávila F.A. 1979. Aspectos epidemiológicos da infecção por Toxoplasma gondii em suínos. Científica. 7: 83-87.

224 Villalobos E.M.C., Cunha E.M.S., Lara M.C.C.S.H. \& Soares R.M. 2005. Ocorrência de anticorpos anti-Toxoplasma gondii em soros de equídeos oriundos de propriedades da região do Vale do Ribeira, Estado de São Paulo e abatidos em matadouro no Estado do Paraná. In: 18ª Reunião anual do Instituto Biológico (São Paulo, Brasil). pp.45-47.

225 Vidotto O. 1992. Toxoplasmose: epidemiologia e importância da doença na saúde animal. Semina: Ciências Agrárias.13: 69-75.

226 Vidotto O., Costa A.J., Reis A.C.F. \& Viotti N.M.A. 1987. Toxoplasmose experimental em porcas gestantes. III. Alterações patológicas e reisolamento. Arquivo Brasileiro de Medicina Veterinária e Zootecnia. 39: 795-814.

227 Vidotto O., Kano F.S., Freire R.L., Mitisuka R., Ogawa L., Bonesi G., Navarro I.T. \& Franciscon F.S.G. 1997. Ocorrência de anticorpos anti-Toxoplasma gondii em equinos procedentes de 4 estados (SP, PR, MS, MT) abatidos em Apucarana, no Paraná. Semina: Ciências Agrárias. 18: 9-13.

228 Vidotto O., Navarro O., Moco C.A., Pincelli C.A. \& Nishimura M.F.C. 1986. Prevalência de Toxoplasma gondii em suínos abatidos em matadouros no Norte do Paraná. In: II Encontro de Pesquisas Veterinárias (Londrina, Brasil). p.23.

229 Vidotto O., Navarro I.T., Giraldi N., Mitsuka R. \& Freire R.L. 1990. Estudos epidemiológicos da toxoplasmose em suínos da região de Londrina - PR. Semina: Ciências Agrárias. 11: 53-59.

230 Wentz I., Sobestiansky J. \& Chaplin E. 1988. Prevalência de anticorpos para toxoplasmose em soros de suínos de pedigree em Santa Catarina. Embrapa. Comunicado Técnico, 3p.

231 Zonta J.C., Araujo F.A.P., Stobbe, N.S., Chaplin E.L \& Silva N.R.S. 1987. Prevalência de anticorpos toxoplásmicos em ovinos de Marau e de Uruguaiana, RS. Arquivos da Faculdade de Veterinária da UFRGS. 15/16: 59-61. 